NBER WORKING PAPER SERIES

\title{
PERSISTENT EFFECTS OF VIOLENT MEDIA CONTENT
}

\author{
Jason M. Lindo \\ Isaac D. Swensen \\ Glen R. Waddell \\ Working Paper 27240 \\ http://www.nber.org/papers/w27240 \\ NATIONAL BUREAU OF ECONOMIC RESEARCH \\ 1050 Massachusetts Avenue \\ Cambridge, MA 02138 \\ May 2020
}

We gratefully acknowledge being included as one of the teams given access to Nielsen data through the NBER-Nielsen Collaboration, led by Andrew Sweeting, Matt Gentzkow, and Jesse Shapiro. Thanks to Dan Feenberg for his invaluable assistance in extracting Nielsen data for our analysis. David Pritchard provided stellar research assistance. We thank Stefano DellaVigna, Matthew Gentzkow, Phil Levine, Patrick Markey, Jesse Shapiro, and Michael Ward for helpful discussions. We gratefully acknowledge the MSU Initiative for Regulation and Applied Economic Analysis for financial support. The views expressed herein are those of the authors and do not necessarily reflect the views of the National Bureau of Economic Research.

NBER working papers are circulated for discussion and comment purposes. They have not been peer-reviewed or been subject to the review by the NBER Board of Directors that accompanies official NBER publications.

(C) 2020 by Jason M. Lindo, Isaac D. Swensen, and Glen R. Waddell. All rights reserved. Short sections of text, not to exceed two paragraphs, may be quoted without explicit permission provided that full credit, including $(\mathrm{C}$ notice, is given to the source. 
Persistent Effects of Violent Media Content

Jason M. Lindo, Isaac D. Swensen, and Glen R. Waddell

NBER Working Paper No. 27240

May 2020

JEL No. H0,K42,L82,L83

\begin{abstract}
We document the immediate and long-term effects of violent media. Specifically, we evaluate the effects of The Ultimate Fighter, a hit TV show that features fighters competing in violent mixed martial arts and which brought Ultimate Fighting Championship into the mainstream. We estimate the effect of early exposure to this show using panel data from police agencies across the United States and a strategy that uses network ratings prior to the show's premier as an instrumental variable. We show that early exposure significantly reduced crime: these effects are particularly evident for assault, began in the month the show premiered, and persisted for many years. These estimates do not reflect systematic differences across geographic areas in their trends in crime rates prior to 2005. To complement our main results, we also investigate the effects of "UFC Main Events," which air in bars and on Pay-Per-View. This analysis additionally suggests reductions in violence caused by viewership.
\end{abstract}

Jason M. Lindo

Department of Economics

Texas A\&M University

4228 TAMU

College Station, TX 77843

and NBER

jlindo@econmail.tamu.edu

Isaac D. Swensen

Department of Agricultural Economics, and Economics

Montana State University

P.O. Box 17290

Bozeman, MT 59717

isaac.swensen@montana.edu
Glen R. Waddell

Department of Economics

University of Oregon

Eugene, OR 97403-1285

waddell@uoregon.edu 


\section{Introduction}

There is a long history of social-science research on the effects of violent media content on anti-social behavior. Laboratory experiments conducted by psychologists, which account for a large share of the rigorous work on this topic, have demonstrated that violent media content increases measures of aggression in the short run. This supports the notion that media violence contributes to social problems, which appears to be the consensus among professionals. ${ }^{1}$ That said, this type of laboratory-based evidence is unable to account for the fact that, in their every day lives, individuals make choices about the media they consume and their behavior is affected by numerous other personal and contextual factors.

The fact that individuals typically choose what media they consume is a challenge for researchers who seek to estimate the causal effects of media violence. Reverse causality is a major threat to estimates of the relationship between violent-media consumption and violent behavior, whether they are based on cross-sectional, time-series, or panel data. For this reason, obtaining credible estimates of the causal effect of media violence requires an external force that alters the media that individuals consume - a force that is otherwise unrelated to violence. The power of laboratory studies is that the experimenter can play this role. That said, laboratory studies have three key disadvantages: (i) they study the effects of media content that individuals may choose not to consume in their every day life, (ii) they do not observe individuals in their natural setting, and (iii) they typically evaluate subjects only over a very short period of time. The pioneering study of Dahl and DellaVigna (2009) overcomes these challenges by using field data and exploiting variation in the consumption of violent media across the United States and over time that is driven by blockbuster movie releases. This earlier work finds no evidence that a violent blockbuster movie increases crime following its release. ${ }^{2}$ In similar spirit, Markey et al. (2015) and Cunningham et al. (2016) examine

\footnotetext{
${ }^{1}$ In 2000, a joint statement from several professional groups concluded that "viewing entertainment violence can lead to increases in aggressive attitudes, values and behavior." In 2009, the American Academy of Pediatrics' issued a statement that the evidence is sufficiently convincing that violence in the media "represents a significant risk to the health of children and adolescents" and that "the debate should be over."

${ }^{2}$ Interestingly, they find evidence that violent-movie releases reduce crime in the evening hours when
} 
crime rates around the release of violent video games, finding no evidence that they increase crime in the short run.

Despite the important contributions of these earlier studies, there are many unanswered questions about the effects of media violence on anti-social behavior. Perhaps most importantly, we know nothing about the long-term effects. ${ }^{3}$ This is critical because prior researchers have highlighted "incapacitation effects" as a likely channel through which violent media content is likely to reduce violent behavior. Put simply, this theory posits that consuming violent media reduces violent behavior because it implies less time doing other activities that are more likely to lead to violence. We believe the prominence of this theory as a candidate explanation for the results found in prior studies underscores the need to examine the long-run effects of a "treatment" involving repeated exposure to violent content over a sustained period of time. One could easily imagine a scenario in which consuming violent media reduces crime in the short run due to incapacitation, but increases crime in the long run due to potential psychological effects that are themselves persistent, or which accumulate through repeated exposure. ${ }^{4}$

We take a step toward filling this void in the literature by estimating the short-, medium-, and long-term effects of early exposure to The Ultimate Fighter (TUF), a hit reality-TV show that features fighters training for and competing in violent mixed martial arts bouts. This show marked the first time that such fights were shown on cable TV and has been credited with bringing Ultimate Fighting Championship (UFC) into the mainstream. In a spirit similar to Kearney and Levine's (2015) study of the effects of the show 16 and Pregnant on

individuals are likely watching the movie and also in the subsequent nighttime hours. They attribute these reductions to an incapacitation effect and reduced alcohol consumption.

${ }^{3}$ The identification strategies used in Dahl and DellaVigna (2009), Markey et al. (2015), and Cunningham et al. (2016) preclude analyses of such effects. Highlighting the difficulty of estimating long-term effects of media violence, a study that follows individuals for three days is described as a "long-term experimental study" in a recent publication in Journal of Experimental Social Psychology (Hasan et al., 2013).

${ }^{4}$ For similar reasons, existing evidence from the lab and the field are not necessarily at odds with one another. Lab-based studies are arguably seeking to identify psychological effects on propensities to engage in anti-social behavior holding context constant. Field-based studies identify the effects on propensities to engage in anti-social behavior inclusive of effects on context that may result from changes in how individuals choose to spend their time. 
teen childbearing, we exploit variation in TUF viewership generated by viewership patterns prior to TUF's premier. In particular, we use Spike TV ratings from the Monday time slot in which TUF would later air (which is based on content that is quite different from TUF) as an instrumental variable for a county's exposure to TUF. Following Kahn-Lang and Lang (2019), we also control for Spike TV ratings across all days and time slots prior to TUF's premier to address the possibility that differences in Spike TV viewership may correlate with crime trends or levels. We argue that the variation induced by this instrument, combined with this control variable, offers an intuitively appealing research design that leverages idiosyncratic variation in viewership - we also provide empirical evidence to support this idea.

Our results indicate that early exposure to UFC content via the first season of TUF significantly reduced anti-social behavior, as measured by monthly reports of crimes filed by police agencies across the United States. Interestingly, the effects are particularly evident for assaults, which is the crime that is most closely related to the content of the show itself, though we find qualitatively similar effects on rape and on property crimes. Moreover, these effects began in the month the show premiered and persisted for many years afterwards. In support of our causal interpretation of these estimates, we show that the variation we exploit is unrelated to pre-existing crime trends and levels. We also find estimates very close to zero in "placebo tests" for effects prior to TUF's premier. Further, using hourly crime data from police agencies across the United States, we provide evidence that similar content depresses violent crime in an analysis of "UFC Main Events," which air in bars and on Pay-Per-View.

Our results provide a new lens through which to understand crime reductions caused by violent media content. In particular, the magnitude and persistence of the effects we document imply a mechanism that is different from a mechanical "incapacitation effect" driven by individuals committing fewer crimes around the time when they are exposed to the new media. The effects are too big to be explained by reductions in crime around the time that those induced into watching TUF by the instrument would have been initially exposed to the show because such a small share of violent crimes are committed on Monday nights, and 
the effects are apparent even during times of the year corresponding to the show's "offseason." While we have no way of determining exactly which mechanisms are relevant, the success of TUF in promoting UFC leads us to believe that early exposure to TUF likely changed time-use beyond the time people would typically spend watching the show on Monday nights, and led to a more-general interest in UFC-related content. As such, the long-run effects we find could be explained by what might be thought of as follow-on incapacitation effects, of a sort, resulting from long-run effects on time-use - time spent in TUF-induced (likely UFC-related) activities that displaces time during which crimes would have been more likely to be committed. However, our results are also consistent with other models of anti-social behavior. For example, it is possible that viewers were put off by the content they viewed on TUF, or that the serious injuries that could result from physical altercations became more salient to them. ${ }^{5}$ It is also possible that viewing UFC content serves as a substitute for engaging in anti-social behavior for individuals with preferences for such behavior - this would typically be described as a "catharsis" or "relief" effect. ${ }^{6}$

In addition to contributing to the literature on the determinants of anti-social behavior, our study also contributes to the growing literature on the real-world impacts of television-media content. In one of the first rigorous studies in this literature, Gentzkow (2006) showed that the introduction of television accounts for up to half of the decline in voter turnout since the 1950s. More-recent studies have found that some types of television exposure improve children's outcomes (Gentzkow and Shapiro, 2008; Kearney and Levine, Forthcoming; Cornelson, 2018), that internet expansion affected sex crime in Europe (Bhuller et al., 2013), and that specific types of media content can have significant impacts on birth rates (La Ferrara et al., 2012; Trudeau, 2016; Kearney and Levine, 2015). ${ }^{7}$ To our knowledge, our study is the first to

\footnotetext{
${ }^{5}$ Such effects could serve to reduce all forms of violence in which individuals' behaviors are determined to some degree by a weighing of costs and benefits (Becker, 1968). Violence is often categorized as instrumental violence motivated by a desire for personal gain, virtuous violence in the service of a societal moral good (Ginges and Atran, 2009; Fiske and Rai, 2014), and impulsive violence which involves a loss of self-control (Dollard et al., 1939; Baumeister and Heatherton, 1996; Card and Dahl, 2011).

${ }^{6}$ Researchers have similarly implicated catharsis or relief effects in suggesting that pornography could reduce sex crimes (Donnerstein et al., 1975; Posner, 1992).

${ }^{7}$ For a survey of the literature on the impact of exposure to the media see DellaVigna and La Ferrara
} 
document the causal impacts of television content on crime.

\section{Background}

\subsection{Violent Media Content and Behavioral Outcomes}

That witnessing violence can increase anti-social tendencies is often thought of through the lens of social learning theory (Bandura, 1977). In this developmental framework, individuals observe the behaviors of others (referred to as models) and consider imitating what they observe based on their own characteristics, the characteristics of the models, and the observed outcomes of the behavior. As a framework for understanding violence, social learning theory finds support from decades of research. While also implicating the roles of parenting, peers, and role models, for example, this literature also includes studies that document correlations between aggression and violent media content. Though the largest part of this literature focuses on violence in television and film, recent efforts have focused on violent video games, often citing concerns surrounding the dramatic increases in time spent on gaming and the intense violence that exists in many popular video games. ${ }^{8}$

In cross-sectional and longitudinal survey data, the measurable correlation between viewing violent content and violent, aggressive, or otherwise anti-social behavior is consistently positive (Eron et al., 1972; Johnson et al., 2002; Anderson et al., 2003; Gentile et al., 2004; Anderson et al., 2010). Importantly, though, this correlation has multiple contributors, one can imagine, some of which are sure to include latent preferences for violent content among individuals with anti-social tendencies, or confounding factors associated with both the viewing of violent media and anti-social behaviors - we think of socio-economic factors, neighborhood characteristics, peer effects, or parental influences, for example. As such, it is unlikely that $(2015)$.

8 This sub-area of study also includes experimental and survey evidence on the internet, music videos and lyrics, television news, initial television access, and other forms of media. Additional studies explore heterogeneity by viewer characteristics, social environments, and various forms of violent media content within each genre (Anderson et al., 2003). 
these studies offer valid estimates of causal effects.

That said, existing laboratory studies employing randomized controlled trials offer evidence of causal effects - seemingly robust evidence that viewing violent content increases aggressive tendencies. Such studies typically take place in laboratories or schools where subjects are randomly assigned varying degrees of exposure to violent content via a short video, film, or through active participation in a violent video game. After being exposed to the content, subjects are asked to interact with each other. While earlier studies allowed direct physical aggression among youth after exposure to violent content (Parke et al., 1977; Josephson, 1987), more-recent studies focus on less-harmful or alternative measures of anti-social tendencies. For example, these include white-noise shocks, electric shocks, physiological arousal, empathy towards others, verbal aggression, and stated attitudes toward violence and hostility (Anderson et al., 2003, 2010; Greitemeyer and Mügge, 2014). To be clear, outcomes in experimental settings are typically far removed from violent crimes such as assault, rape, and murder. As such, laboratory studies provide limited insight into the extent to which violent media affects more-serious forms of violent behavior.

Another limitation of laboratory studies is that they can only measure short-term effects, while subjects are observed in the lab. The typical experiment measures immediate effects shortly after a single exposure. Moreover, even "longer-term" experimental studies involving cumulative exposure are still limited to short windows. For instance, Hasan et al. (2013) characterize their analysis over a three-day window as "the first experiment to test the cumulative causal effects of violent video games on aggression over a relatively long period of time." The degree to which repeated exposure affects behavior over a longer timeframe remains an important outstanding question.

As a whole, these laboratory studies provide compelling evidence that viewing violent media can increase aggressive anti-social tendencies. As such, it is perhaps not surprising that researchers and health organizations have made strong statements concluding that "the 
debate is over" regarding the effects of violent media content. ${ }^{9}$ That said, experimental analyses in the lab do not replicate real-world choices to view media content, choices that may be influenced by alternative activities, content-specific contextual factors, possible coping mechanisms, and wide-ranging content-specific preferences over media consumption. In short, the controlled approach that lends to a causal interpretation of results obtained in the lab may severely limit the generalizability of the findings to real-world effects of violent-media consumption.

Attempting to fill this critical gap in the literature and overcome many of the limitations of the lab, Dahl and DellaVigna (2009) use a quasi-experimental approach to analyzing violent crime around blockbuster movie releases. They find that blockbuster movies with relatively high violent content decrease assaults the night of the movie, with especially large declines in the hours following the conclusion of normal showtimes. Exploring mechanisms, they provide evidence that incapacitation reduces assaults during the movie, and substitution away from alternative activities (e.g., going to the bar) likely drive the larger reduction in assaults after the movie. These results highlight that the effects of choices to view violent content in real-world contexts may be very different from the effects found in laboratory settings. Notably, Dahl and DellaVigna (2009) find no effects in the three weeks following exposure, though they acknowledge that their empirical approach is not well suited to estimate longer-run effects. It is also not well suited to estimating the effects of repeated exposure to violent content. In contrast, the treatment we consider (early exposure to UFC content) is understood to have generated the sort of fandom that entails frequent repeated exposure over a sustained period of time.

Also offering evidence on the effects of violent media content, Cunningham et al. (2016) use an instrumental-variables strategy to estimate the effect of popular video-game releases on violent crime. They describe their results as indicating "no evidence of an increase in crime associated with video games and perhaps a decrease." Markey et al. (2015) provides

\footnotetext{
${ }^{9}$ See, for instance, Anderson et al. (2003) and Bushman and Anderson (2015), and the 2000 joint statement from the American Academy of Pediatrics on the Impact of Entertainment Violence on Children.
} 
suggestive evidence that violent video games reduce violent crime using variation in video game release dates, video game sales, and keyword searches for violent video game guides. ${ }^{10}$ As with Dahl and DellaVigna (2009), these estimates are not consistent with the idea that violent media content increases violent behavior, and thus further suggest a tension between the positive effects found in the large lab-based literature and negative effects found in quasi-experimental studies.

Together, this recent evidence offers important insights into the effects on anti-social behavior caused by individuals' choices to view violent media content. Importantly, none of the existing studies - whether using survey data, experimental data, or data from the field - speaks to the long-run effects of repeated exposure. Our research contributes on this important margin.

\subsection{The Ultimate Fighter and the Rise of the UFC}

It's amazing to think how close we came to not being here today. If it weren't for what these guys did, I don't know if there would even be a UFC.

-UFC President, Dana White, at the The Ultimate Fighter "Season 1 Reunion" three years after it aired.

The Ultimate Fighter (TUF) is widely credited as having brought mixed-martial arts, and the Ultimate Fighting Championship (UFC) in particular, into the mainstream. The UFC began organizing and promoting mixed-martial-arts events, which aired on Pay-Per-View, in the early 1990s. These fighting tournaments had minimal rules, no weight classes, took place in a cage, and were famously referred to as "human cockfighting" by Senator John McCain in 1996 who lobbied to have the events banned. As a result, the events were banned in every state with an athletic commission, making it difficult for them to be held in major markets. During this period of time, UFC held events in Iowa, Mississippi, Louisiana, Wyoming, and Alabama. In 1998 the UFC lost its Pay-Per-View distribution. The UFC subsequently modified its rules

\footnotetext{
${ }^{10}$ In a related context, Ward (2011) finds lower growth in crime rates in counties with relatively high rates of growth in video-game stores. Ward (2199), instrumenting for own video-game playing with peer video-game playing, finds no support in Add Health surveys for a causal relationship running from video game playing to aggressive outcomes.
} 
and eventually secured sanctioning from California and New Jersey in 2000, thus allowing the company to hold events in these states under the supervision of their athletic control boards. Despite these steps towards legitimacy, the UFC was sold for just $\$ 2$ million in January 2001.

New ownership did not lead to an immediate turnaround for UFC. UFC returned to Pay-Per-View in late 2001 but events averaged only 150,000 Pay-Per-View buys in the following three years. By 2004, the new ownership group had lost $\$ 34$ million since 2001. The ownership group subsequently doubled down on their investment in UFC, spending $\$ 10$ million dollars to produce the reality TV show, The Ultimate Fighter. ${ }^{11}$

TUF premiered on a Monday night (January 17, 2005) on Spike TV, which was promoted as "The First Network for Men." It aired weekly, in the time-slot following the wrestling entertainment program, WWE Raw. The Spike TV content airing in November 2004 was for the most part quite different from TUF. The shows airing in November 2004 in what would later become TUF's time slot included a comedy show featuring comedic actors narrating footage from a Japanese game show from the 1980s (Most Extreme Elimination Challenge, five times), a professional wrestling show (WWE Velocity, one time), a reality show about young men quitting their jobs to pursue their dreams (I Hate My Job, two times), a show about a video game (Need for Speed: Underground 2, one time), and a reality show featuring a video game superfan (Ultimate Gamer, one time). Between November 2004 and the premier of TUF, the shows airing in this time slot were Most Extreme Elimination Challenge, Ultimate Gamer, 2004 Video Game Awards, The World is Not Enough (1999 James Bond film), and Most Amazing Videos.

That said, it might be tempting to suggest that treatment here is merely one additional hour of violent content. However, we see the advent of UFC on Spike as a significant inducement mechanism into exposure to violence and inducing a scale of fandom that is still impressive. In the two years after the show aired on Spike TV, UFC's revenue increased

\footnotetext{
${ }^{11}$ Previously, the same ownership group had success in promoting their casinos through the reality TV series, American Casino.
} 
$1,258 \%$, including a $1,700 \%$ increase in Pay-Per-View sales. ${ }^{12}$ The media's representation of the period is also decidedly one sided, with claims such as "Nothing really goes back to 'normal' after The Ultimate Fighter. Not Spike. Not the UFC." ${ }^{13}$ We return to this point below.

What may have made the difference for the TUFs success is that it followed a format similar to other reality shows, bringing together contestants to live and interact in the same residence under nearly constant surveillance. TUF content is distinct from other reality shows in its focus on fighters training for and participating in violent and often brutal mixed-martial-arts bouts that occur in each episode as a part of a season-long tournament for a "six-figure UFC contract." These bouts as well as the preceding training and sparring display frequent injuries, blood, choking, and similar content typical of mixed-martial-arts events where the goal is to knock out or submit your opponent. ${ }^{14}$ It also features UFC stars as coaches and guests.

TUF was considered an instant ratings success, as 1.7 million viewers tuned into the initial episode. This represented a 36 percent increase over the shows that aired on the same day and time slot in the previous year. The show continued to be popular throughout the season and ultimately drew three-million viewers to its finale. TUF was considered Spike TV's first hit show and led to the production of UFC Unleashed, which aired fights from past

\footnotetext{
12 Source: https://www.theguardian.com/sport/2016/mar/04/the-fight-game-reloaded-how-mmaconquered-world-ufc

${ }^{13}$ Source: https://www.bloodyelbow.com/2017/2/14/14600570/inside-the-ultimate-fighter-why-the-realityshow-was-is-so-important

14 While TUF centers on the fights, it also features the backgrounds of fighters in addition to drama, aggression, and conflict among competing fighters living together. While the structure of the show varies over its 27 seasons, the usual format divides between 14 and 32 contests into two teams as they live together, train together, and compete in fights. Each episode features at least one fight, the loser of which is eliminated from the tournament while the winner advances to the next round of fights. TUF has sparked careers for a large number of fighters, including many who did not win the competition. As such, TUF fights are central to the show not just because they determine who wins the competition in a given season, but also because they provide a unique opportunity for participants to earn recognition and credibility from UFC executives and a national television audience which can promote their professional careers. Eighteen TUF participants (including seven who did not win their TUF season) have fought for a title and eight have become UFC champions according to https://tvtropes.org/pmwiki/pmwiki.php/Series/TheUltimateFighter. The coaches for each team are typically UFC star fighters who are scheduled to fight against each other in the featured bout in the UFC Pay-Per-View event following the conclusion of the TUF season. These fights are heavily promoted as the TUF season finale approaches.
} 
UFC events, UFC Fight Night, which aired fights live, and UFC Countdown specials, which promoted upcoming events that were scheduled to air on Pay-Per-View. Naturally, it also spawned many subsequent seasons of TUF - two annually - and is now in its 27th season. As indicated by the UFC President's quote at the beginning of this section, TUF is widely viewed as a turning point for UFC's popularity. A Yahoo Sports article describes TUF as having "broke the UFC through to the masses." 15

This sentiment appears to be borne out based on an analysis of UFC's Pay-Per-View events, which continued to be held intermittently throughout the year, and which individuals could pay to view through their cable provider. In Panel A of Figure 1 we report annual Pay Per View buy rates (across all events), which ranged between 278,000 and 415,000 between 2002 and 2004, doubled in 2005, and then exploded to more than five million for many years thereafter. ${ }^{16}$ An analysis of Google searches between 2004 and the end of 2016 - the results of which are shown in panels $\mathrm{B}$ and $\mathrm{C}$ of Figure 1 - also demonstrate the sizable and sustained interest in UFC that followed the premier of TUF. Indeed, search activity for UFC grew after the TUF premier such that it was comparable to searches for Oprah and Beyonce by the middle of 2006, and such that it outstripped search activity for CSI, which was the highest rated television show when TUF premiered and which was typically among the highest rated shows throughout the 2000s. In contrast, peak search activity for the show 16 and Pregnant, which has been credited with reducing the United States teen birth rate by 4.3 percent in the 18 months after it began airing in 2009 (Kearney and Levine, 2015), is an order of magnitude lower. Searches for UFC also grew to be comparable to searches for other cultural touchstones appealing to young men, including Call of Duty (the highest grossing video-game franchise in the first-person shooter genre of all time) and the NHL (the fourth most searched professional sport in the United States) while usually outstripping searches for LeBron James and Tom Brady (who were arguably the most popular athletes in the NBA and NFL, respectively,

\footnotetext{
15 https://sports.yahoo.com/ufcs-25th-anniversary-look-25-slideshow-wp-080028231/photo-p-2005-ultimatefighter-reality-photo-080028393.html.

${ }^{16}$ Data available from https://thesportsdaily.com/2018/02/16/all-time-ufc-ppv-sales-data-fox11.
} 
during the 2000s). As a whole, the results shown in Figure 1 highlight the cultural importance of the UFC, which gives credence to the notion that the show responsible for its popularity (TUF) may have had significant impacts on outcomes such as crime.

\section{Data}

In order to measure TUF viewership, we use data collected by Nielsen, the primary source for measuring exposure to television content in the United States. Nielsen collects show ratings data from an array of sources including diaries, in-home metering and audio-recording meters worn by participating individuals. They do so primarily during specific "sweeps months" of the year, not throughout the entire year. We use their county-level data on: Season 1 TUF viewership measured during February 2005; Spike viewership in the same time slot in November 2004 (prior to TUFs premier); and overall Spike TV viewership measured during November 2004. Our data extracts from Nielsen allow us to calculate ratings for 55 percent of the United States population. ${ }^{17}$

Our main source for crime data is the Uniform Crime Reports (UCR) Offenses Known and Cleared by Arrests segment, which are a compilation of monthly crime statistics contributed to by law-enforcement agencies across the United States to the FBI. ${ }^{18}$ We focus on known offenses in order to capture crimes that come to the attention of law enforcement, as opposed to restricting crimes to those that have been cleared by arrest. UCR data also include annual estimates of the populations covered by each agency, which we use to calculate agency specific crime rates, per 10,000 residents. We restrict our sample to municipal police agencies and agency-years with 12 months of submitted crime reports. We then combine our UCR sample with county-level Nielsen ratings data, keeping UCR agencies for which Nielsen data are

\footnotetext{
${ }^{17}$ Due to the structure of the data request process, which required us to identify specific networks, dates, and time periods, and because the show aired at slightly different times in different time zones, we do not have accurate measures for all of these variables outside of the Pacific, Central, and Eastern time zones. Data are also missing for counties from which Nielsen did not collect data in a given sweeps period.

18 The UCR Offenses Known data used in this study were collected and compiled by the Inter-University Consortium for Political and Social Research (ICPSR).
} 
available. ${ }^{19}$ The resulting sample includes crime data from 8,750 municipal agencies in 41 states, spanning 2001-2016. In Table 1 we present summary statistics for this sample.

\section{Empirical Strategy}

Our identification strategy exploits the fact that people exhibit some degree of habit persistence in television viewing, and this habit persistence causes some individuals to watch TUF when it began airing who otherwise would not have watched the show (perhaps until learning about it later). To fix ideas, consider someone who frequently watches Spike TV on Monday nights in 2004. We would expect this person to be more likely than others, all else equal, to watch TUF when it begins airing in January 2005 on Spike TV on Monday nights. This is the sort of variation we seek to exploit, in a spirit similar to Kearney and Levine (2015) who analyze the effect of MTV's 16 and Pregnant on teen childbearing using "pre-treatment" MTV viewership in the relevant time slot as their instrument.

Just as 16 and Pregnant was very different from the content that made up Kearney and Levine's instrument, which helps to address concerns about selection bias, the Spike TV content airing in November 2004 was for the most part quite different from TUF (as we described in Section 2.2). That said, a skeptical reader may still be concerned that crime propensities are correlated with watching Spike TV on Monday nights in 2004. After all, men are more likely to commit crimes than women and Spike TV was promoted as "The First Network for Men." 20

For this reason, we focus specifically on variation driven by 2004 Spike TV viewership in the relevant time slot (in which TUF would later air) controlling for overall 2004 Spike $T V$ viewership. As such, the thought experiment is a comparison of individuals who watch

\footnotetext{
${ }^{19}$ Ratings data is available for 74 percent of agencies in our UCR sample.

${ }^{20}$ It is along these lines that Jaeger et al. (2016, 2020) critique the Kearney and Levine (2015) analysis of the effects of MTV's 16 and Pregnant. Specifically, Jaeger et al. highlight that there are significant level differences in outcomes associated with the instrument and that there is also evidence of differential trends in outcomes associated with the instrument. In response, Kearney and Levine (2016) make the case that evidence of differential trends during an extended pre-treatment period does not imply that there are differential trends over the relevant period of time.
} 
the same amount of Spike TV in 2004 overall, but one set of individuals typically watches in the (future) TUF time slot while the other set of individuals watches at other times. As a result of habit persistence, initial rates of TUF viewership will be higher for the first set of individuals than for the second set of individuals - that is, there will be a "first-stage" effect on early exposure to TUF. Under the assumption that crime propensities are the same for the two sets of individuals, we could estimate the effect of early exposure to TUF by comparing crime rates across the two groups after TUF begins airing, and inflating this reduced-form estimate by the estimated first stage. With data on crime rates prior to TUF, however, we can then relax this assumption by comparing changes in crime rates across the two sets of individuals. The validity of this approach rests on the common trends assumption generally required by difference-in-differences designs.

To operationalize this strategy, data availability requires us to use county-level ratings data and crime data from police agencies that are nested within counties. As such, we cannot think about these data as offering the two convenient sets of individuals described in the thought experiment outlined above. Nonetheless, the same sort of variation can be exploited via two-stage least squares. In particular we estimate the following first-stage regression equation

$$
\text { RateTUF } F_{a c}=\psi_{0} T U F_{-} \text {TimeSlot } 04_{a c}+\psi_{1} \text { Spike } 04_{a c}+u_{a c},
$$

where RateTUF $F_{a c}$ is the Season 1 TUF rating for agency a's county c, RateTUF_TimeSlot04 ${ }_{a c}$ is the 2004 rating for the time slot in which TUF would later air (excluded instrument), RateSpike $04_{a c}$ is the 2004 rating for Spike TV overall, and $u_{a c}$ is a random error.

To evaluate the effects of TUF viewership on crime, the second-stage regression equation uses variation in RateTU$F_{a c}$, the predicted Season 1 TUF rating. Specifically, the second-stage equation is

$$
y_{a c t}=\beta_{0} \widehat{T U F_{a c}} \times \text { Post }_{t}+\beta_{1}{\text { Spike } 04_{a c}} \times \text { Post }_{t}+\theta_{a c}+\delta_{t}+\epsilon_{a c t}
$$


where $y_{a c t}$ is the natural $\log$ of the crime rate for police agency $a$ in county $c$ at time $t$, RateTU $F_{a c}$ is the predicted Season 1 TUF rating based on the first stage, RateSpike04 $4_{a c}$ is defined the same way as in Equation (1), $\theta_{a c}$ are agency fixed effects that capture any fixed differences across agencies with time-invariant impacts on crime, $\delta_{t}$ are time-period fixed effects that capture any time-varying shocks to crime that are common across agencies, and $\epsilon_{\text {act }}$ is a random error term. ${ }^{21,22}$

Without the term $\beta_{1}$ RateSpike04 ${ }_{a c} \times$ Post $_{t}$, Equation (2) would be identical to the twoway fixed effects model that is commonly used for circumstances in which researchers seek to exploit variation in treatment intensity to estimate treatment effects under a difference-in-differences-like identifying assumption: that the variable generating treatment intensity (RateTUF_TimeSlot04ac) is unrelated to trends in the outcome. By including $\beta_{1}$ RateSpike $04_{a c} \times$ Post $_{t}$ in the model, we relax this assumption. Specifically, this term captures the expected changes in crime rates over time for areas with different levels of overall 2004 Spike TV viewership. As such, the inclusion of this term makes it such that our estimates are identified by comparing changes in crime for areas with relatively high ratings in the TUF time slot before it aired to changes in crime for counties with relatively low ratings in the TUF time slot before it aired adjusted for the differences in crime that are expected over time across areas with different levels of overall 2004 Spike TV viewership.

We take this approach, additionally controlling for $\beta_{1}$ RateSpike $04_{a c} \times$ Post $_{t}$, to address potential concerns that there may be differences in trends associated with 2004 Spike TV

${ }^{21}$ For simplicity, we refer to the outcome variable in the text as the log of the crime rate. However, to address the fact that the number of crimes may be zero in some instances, making the natural log undefined, we transform counts using the inverse hyperbolic sine transformation. As such, the outcome variable is defined as $\ln \left(\frac{\text { count }+\sqrt{\text { count }}{ }^{2}+1}{\text { population }}\right)$. We take this approach in order to use all of the data but it has little influence on the resulting estimates because the observations for which it is relevant are given little weight in our (WLS) regressions, and we show that the results are similar extremely similar if we use alternative transformations.

${ }^{22}$ An alternative expression of the first- and second-stage equations that emphasizes the panel structure of the data (agency-within-county-by-time) is:

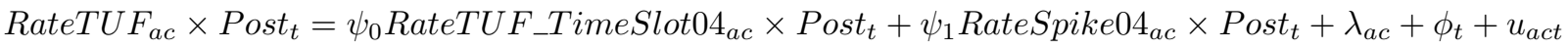

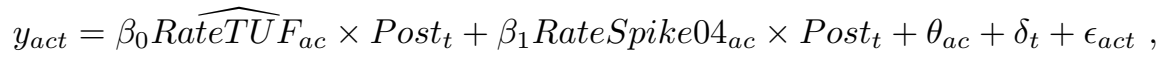

where all of the variables are defined the same as above. 
ratings for the relevant time slot. It is motivated by Kahn-Lang and Lang (2019) discussion of the exchange between Kearney and Levine (2015, 2016) and Jaeger et al. (2016, 2020), which highlights the importance of examining what factors might explain differences in pre-treatment outcome levels even if such differences are being differenced out in a difference-in-difference design. Specifically, they argue: "[i]f we understand why the experimental and control groups differ in levels, we may better understand whether to anticipate common or divergent trends." They go on to explain that we can be relatively "confident that we have solved the problem with nature's design of the experiment" if we are able to identify a control variable that eliminates initial differences in outcomes (as well as any differences in pre-treatment outcome trends) associated with treatment. In the next section, we show how controlling for Spike TV's overall rating in 2004 accomplishes this in our setting.

A few additional details of our analysis are worth mentioning. First, in order to improve efficiency we use weighted-least squares, with agency jurisdiction populations as weights. Second, our standard-error calculations allow errors to be correlated within counties over time. ${ }^{23}$ Third, we typically estimate the effects for different periods of time in an event-study type of analysis. To do so, we include in the model a set of indicators for periods of time leading and lagging Season 1 of TUF in the model instead of the single variable, Post . $_{\text {. }}$

\section{Evidence for the Validity of the Research Design}

In this section we begin by showing that we have a strong first stage and then show evidence to support the exclusion restriction required by our instrumental variables empirical strategy.

\footnotetext{
${ }^{23}$ Because the police agencies we consider are nested within counties, this implies that we are also allowing errors to be correlated across police agencies in the same county. Our choice to cluster the standard errors at the county level is motivated by the fact that the variation we exploit is at the county level and a desire to address "design-based uncertainty" with regards to the natural experiment we exploit (Abadie et al., 2020). Because the outcomes we analyze (crime rates) are based on all known crimes rather than a sample of crimes, we anticipate little "sampling-based uncertainty" in our data, driven only by the fact that population counts are typically measured with error. Nonetheless, we have also estimated standard errors allowing for clustering at the Nielsen Designated Market Areas (DMA) level, which combine counties into roughly 200 areas. This approach produces extremely similar estimates.
} 


\subsection{First-Stage Estimates}

In Figure 2 and Table 2 we demonstrate the strength of the first stage. Specifically, the first graphic in Figure 2 plots Season 1 TUF ratings (measured in February 2005) against Spike TV ratings for the same time slot before TUF premiered (measured in November 2004), with marker sizes that vary with the population of the area it represents. The weighted-least-squares estimate for this relationship, shown in column (1) of Table 2, indicates that a one-percentage-point higher rating in the relevant time slot before TUF premiered is associated with a 0.62 percentage-point higher TUF rating.

As we discussed in detail in Section 4, this relationship may simply reflect relatively high rates of TUF viewership in areas where a relatively large share of the population watched Spike TV prior to TUF's premier. This is not the sort of variation we seek to exploit. Our thought experiment is a comparison of individuals who watch the same amount of Spike TV prior to TUF's premier, but one set of individuals typically watches in the (future) TUF time slot while the other set of individuals watches at other times. The aggregate-data analogue is to exploit differences in pre-TUF ratings across days and times among areas with the same overall Spike TV ratings.

The second graphic in Figure 2 depicts this variation, by plotting Season 1 TUF ratings adjusted for pre-TUF overall Spike TV ratings against Spike TV ratings for the same time slot before TUF premiered also adjusted for pre-TUF overall Spike TV ratings. While a bit weaker than the relationship depicted in the unadjusted plot, it again shows a strong positive relationship that is additionally evident in the weighted-least-squares estimate shown in column (2) of Table 2. This first-stage estimate has an F-statistic of 80 and indicates that one percentage-point higher rating in the relevant time slot before TUF premiered-holding overall Spike TV ratings constant - is associated with a 0.52 percentage-point higher TUF rating. While we cannot determine whether this is due to habit persistence or advertising, this estimate supports our hypothesis that TUF would have relatively high rates of initial viewership in areas where a relatively large share of the population watched Spike TV in its 
time slot before it premiered even after controlling for overall Spike TV ratings.

\subsection{Exclusion Restriction, Common Trends, Common Levels}

Given our difference-in-differences identification strategy, in order to be valid the instrument must be unrelated to changes in violent crime following TUF's premier that would be expected in the absence of the show (conditional on covariates). Given that we are conditioning on overall Spike TV ratings, our instrument can be thought of as capturing the degree to which residents of an area tended to watch Spike TV in the future TUF time slot versus watching Spike TV at other times among areas where residents watch the same amount of Spike TV overall. While we cannot say that this is random, we believe it is the sort of idiosyncratic difference that makes for a convincing instrument if it can also hold up to closer scrutiny.

As a first pass at examining the degree to which this variation appears to be "as good as random," in Figure 3 we show a map of the United States that depicts this variation. It demonstrates significant variation all across the country -importantly, it does not appear as if the instrument takes particularly large values in any particular region, or in places that we would expect to have particularly high (or low) crime rates or trends in crime rates.

We more formally examine the degree to which the variation we exploit is related to pre-TUF crime rates in Figure 4. Specifically, in Panel A we focus on 2004 log of violent crime rates and in Panel $\mathrm{B}$ we focus on the change in the log of violent crime rates from 2001 to 2004. Although the graphics labeled "Unadjusted" shows that the levels and the trends of our outcome measure are positively related to pre-TUF Spike TV ratings in the relevant time slot, the graphics labeled "Adjusted" demonstrate that controlling for pre-TUF Spike TV ratings overall eliminates these relationships. In other words, the slope coefficients and standard errors provided in the figure reveal statistically significant estimates in the "Unadjusted" plots, while the "Adjusted" plots reveal no such significance. Using the language of Kahn-Lang and Lang (2019), that we have a control variable that eliminates both the initial difference and differential trends allows us to feel "confident that we have solve[d] the 
problem with nature's design of the experiment." Thus, it provides support for the untestable assumption that the variation we exploit is unrelated to the crime trends that would have been observed in the absence of TUF. ${ }^{24}$

\subsection{Main Results}

Having provided evidence to support our research design, we now present estimates of the causal effects early viewership of The Ultimate Fighter (TUF) in order to speak to the short-, medium-, and long-term effects of exposure to violent media content on crime. We estimate the causal effect exploiting variation in TUF viewership generated by geographic differences in viewership prior to TUF's premier, and its role in explaining the variation in first-season viewership. Specifically, we use Spike TV ratings in the same Monday time slot in which TUF would later air as an instrumental variable for a county's early exposure to TUF.

In Figure 5 we plot second-stage coefficient estimates from the event-study type of specification corresponding to our identification strategy, evaluating the effects on violent crimes. $^{25}$ Specifically, for each quarter we plot separate estimates of the effect of TUF on crime in the years overlapping with seasons 1 through 20, from 2005 through to the end of 2014. ${ }^{26}$ We also plot estimated "effects" for each quarter of the years prior to TUF's premier, which serves as a set of placebo tests for effects prior to TUF's premier. The omitted time periods represented by the "pre" period are those in 2001 and 2002. As discussed above, in addition to the indicator variables capturing time periods leading and lagging TUF's premier interacted with its Season 1 rating (which we instrument for using pre-TUF ratings in the

\footnotetext{
${ }^{24}$ Another identifying assumption not discussed in detail here is that pre-TUF Spike TV ratings in the relevant time slot not have any direct impacts on crime rates after the TUF premier. Given the content that was typically in that time slot - a variety of game shows and adult animated comedy, for example - we think this a reasonable assumption. This position is reinforced by the fact that our analysis does not find any evidence of impacts on crime prior in the year leading up to the TUF premier and we find evidence of an immediate impact on crime when TUF begins airing.

${ }^{25}$ Our measure of violent crime includes assault (simple and aggravated), rape, and murder.

${ }^{26}$ We also plot one pooled estimate for observations in 2015 though 2016, overlapping with seasons 21 through 24 , though they do not deviate from zero if we separately identify each of them. In nearly all instances, seasons spanned three months and there were three months between seasons - this pattern was only interrupted by some slight changes following Season 16 .
} 
relevant time slot), the model also controls for the same indicator variables interacted with pre-TUF Spike TV ratings overall in addition to agency fixed effects and time fixed effects.

There are three main takeaways from the set of violent crime estimates depicted in Figure 5, which are reinforced by reduced-form estimates shown in Appendix Figure A7 and the estimates that additionally adjust for time-varying control variables shown in Appendix Figure A9. First, the variation in early exposure to TUF that we exploit was unrelated to the evolution of violent crime rates leading up to the show's premier. In all categories of violent crime, the placebo estimates for the quarters leading up to the show's premier are all very close to zero and exhibit no evidence of any relevant differences in pre-existing trends. This evidence is consistent with the results presented in Figure 4, which demonstrated that violent-crime-rate trends and levels were unrelated to the instrument after controlling for pre-TUF Spike TV ratings overall.

Second, we see an immediate effect on the violent crime rate with the commencement of Season 1 (Panel A). Indeed, if one considers the estimated effects for all 48 time of the periods depicted in Panel A of Figure 5, the largest change in the estimated effect from one period to the next occurs exactly when TUF began airing (in the first quarter of 2015). This is indicative of an effect that is highly statistically significant based on the notion of "in-time placebo tests" as discussed in Heckman and Hotz (1989) and Abadie et al. (2015). This pattern is also evident for assaults (Panel B) and to a lesser degree for rapes (Panel C), while there is no evidence of effects on murder (Panel D). In Appendix Figure A9, we present an even more disaggregated set of estimates that demonstrates that the effect on violent crimes appears in the first month of TUF's airing and that there is no evidence of such declines in the three months leading up to the premier. That the effect is so precipitous with show's premier lends confidence to the validity of our research design and the statistical significance of the effect because it is hard to imagine what sort of confounder could lead to such results.

The third and most-striking takeaway from the set of estimates depicted in Figure 5 is that the effects persist beyond the period of time spanned by TUF's first season (Q1 2005). 
Indeed, the effects appear to persist into the "off season" after the first season was completed and before the second season began (Q2 2005) and all the way through at least 2012 (i.e., through eleven or twelve seasons of TUF and the off seasons in between). This pattern is likewise evident for the subcategories of assault and rape - evidence of effects that are immediate and only seem to attenuate some five years after the show's premier.

These results naturally raise the question: why would initially persistent effects eventually fade out? We believe this is likely the result of two counteracting mechanisms. Intuitively, the initial effects may be be sustained or even grow if individuals affected by the instrument become bigger and bigger fans of UFC content over time. At the same time, while the instrument generates variation in who becomes a UFC fan in early 2005, in the long-run nearly everyone will hear about the UFC and those who are inclined to like it will become fans. Thus, the effect of early exposure to UFC content via TUF's first season should be expected to die out at some point in time.

Another feature of the pattern of estimates depicted in Figure 5 is that the effects appear larger in the first and third quarters of each year. This may be due to the fact that these quarters closely overlapped with new seasons of the show as opposed to off seasons in which new episodes were shown, but it may also be a statistical aberration. ${ }^{27}$

In Figure 6 and Appendix Figure A7 we report second-stage and reduced form results, respectively, for property crimes. These figures show a very similar pattern as Figure 5-they raise no concerns about differential trends prior to TUF's premier and suggest an immediate and persistent effect on crime after the show begins airing. The effects are also similar for the separate categories of theft, motor-vehicle theft, and robbery. ${ }^{28}$ Notably, however, estimates of the effect on property crime are more imprecise.

While the estimated effects shown in Figure 5 and Figure 6 are informative, we are knowingly giving up precision in this figure to be able to estimate a large number of parameters that help us to assess the research design and to get a sense of the timing of

\footnotetext{
27 Reruns of prior seasons would typically be aired when new episodes were not shown.

28 Property crime includes theft (larceny and burglary), motor-vehicle theft, and robbery.
} 
the treatment effects. Having provided this evidence, in Table 3 we present estimates from more-parsimonious models that pool together the time periods spanned by the first five years following TUF's premier and, separately, the time periods afterwards. In discussing the effects, we focus on implied effects of a tenth of a percentage-point increase in TUF Season 1 ratings which is more reasonable than a one-percentage point increase given that the mean rating is 1.59 (with a standard deviation of 1.55).

The estimate in column (1) of Panel A indicates that a 0.1 percentage-point increase in TUF Season 1 ratings reduces violent crime by $0.64 \%$ over five years. Across subcategories of violent crime, shown in columns (2) through (4) of Panel A, we find that the estimated effects are largest for assaults $(-0.63 \%)$, somewhat smaller for rape $(-0.26 \%)$, and close to zero for murder. Consistent with our prior evidence that the effects eventually fade away, the estimated effects are never statistically significant for the time period after 2009. Despite suggestive evidence of effects on property crime in Figure 6, pooled estimates of the effect on rates of property crime are not statistically significant in the aggregate or in any subcategory.

We suggest that readers exercise caution with regards to the magnitude of these estimated effects. While the estimates indicate a statistically significant effect on violent crime, the 95\% confidence interval includes both effects that would be considered small in magnitude and effects that would be considered large in magnitude. To put the estimate and their associated confidence intervals into perspective, note that a 0.1 percentage-point difference in TUF Season 1 viewership corresponds to 1,202 additional viewers in the average county. ${ }^{29}$ The two-stage-least-squares estimate from Table 3, Panel A, column (1) indicates that such an increase in viewership reduces violent crime by 0.64 percent $(95 \%$ CI: $0.012,1.26)$, or 8.7 fewer violent crimes per month in the average county (95\% CI: 0.16, 17.13). As such, the point estimate implies roughly 7.2 fewer violent crimes monthly per 1,000 individuals exposed to the show during its first season (95\% CI: 0.14, 14.28). For broader context, however, it's also worth noting that the target audience for both the network (Spike TV) and the show

\footnotetext{
${ }^{29}$ A 0.1 percentage-point change in TUF viewership corresponds to a 9.4 increase in viewership, and the (population-weighted) average county size represented in our analysis is 1.2 million.
} 
itself (TUF) were the same as the demographic group responsible for a disproportionate share of violent crimes-young men.

In summary, using variation in pre-TUF viewership in the time slot that would later become the time slot of TUF — while controlling for differences in overall Spike TV viewershipwe identify systematic reductions in violent crime associated with viewership of the show's first season. These reductions are driven by the category one might anticipate being most responsive given that TUF (and UFC) essentially features assaults sanctioned by athletics commissions. ${ }^{30}$ These effects begin with the show's premier, and persist for at least five years. In support of a causal interpretation of these estimates, the estimated effects are very close to zero in "placebo tests" for effects prior to TUF's premier and estimates that are routinely negative for a long period of time thereafter.

\subsection{Supplementary Analysis of "UFC Main Events"}

Though our primary objective in this paper is to evaluate the long-run effects of violent media content, our main results are arguably more credible if we can demonstrate an even more immediate response or, in some sense, some more locally identified proof of concept. In the prior section, we noted that the effects of early exposure to TUF become apparent in the very month in which the show premiered. In this section, we take an additional step towards understanding how the sort of content featured on TUF-violent mixed martial arts bouts - affects behaviors in the short run. We do so by analyzing the effects of "UFC Main Events" using hourly crime data from police agencies across the United States. These events air live in bars and on Pay-Per-View and showcase fights involving top UFC fighters, usually including a title fight for one or more weight divisions. The fact that these events are scheduled irregularly throughout the year is a distinct advantage that is critical to the empirical strategy that we use in this section, which compares how rates of crime change

\footnotetext{
30 Though we think it is reassuring for the validity of the research design that the estimated effects are most prominent for assault, we think it important to note that nothing precludes TUF viewership from having impacts on many different forms of anti-social behavior. Thus we think it inappropriate to think of estimated effects on other crime outcomes as "placebo tests."
} 
around the time of these events relative to the same times on otherwise-similar days.

For this analysis, we identify start times for 91 UFC Main Events, spanning August 2010 through December 2016. ${ }^{31}$ To measure hourly crime rates, we use data from the National Incident Based Reporting System (NIBRS) collected by the Federal Bureau of Investigation (FBI). NIBRS is a voluntary program that collects detailed information on crime incidents from law-enforcement agencies across the United States. Though there are far fewer agencies included in NIBRS than in the UCR program, NIBRS identifies the date and hour of incidents known to municipal law enforcement agencies, facilitating our analysis of short-run changes in crime that occur around UFC Main events. As all but one UFC Main event in our time frame occurred on a Saturday, we restrict our sample to Saturdays - specifically, we consider hours from Saturdays at 6am to Sundays at 5:59am, the following morning. This results in a data set including 15,144,168 agency-hour observations based on 3,771 municipal law enforcement agencies in 34 states. We focus on assault, the crime outcome for which we saw the clearest evidence of effects in our main results, and on assaults in bars given that bars typically air these events.

To identify the short-term effect of UFC Main Events, we employ the following model:

$$
y_{\text {aymh }}=\sum_{j=-10}^{16} \beta_{h} \mathbb{1}\left(\text { HoursFromEvent } t_{\text {aymh }}=j\right)+\theta_{\text {ay }}+\delta_{a m}+\gamma_{s h}+\epsilon_{\text {aymh }},
$$

where $y_{\text {aymh }}$ is the $\log$ of the number of reported offenses per 10,000 residents in agency $a$ in year $y$ in month $m$ in hour $h .^{32}$ The set of parameters $\beta_{h}$ traces out the effects during the hours leading up to, during, and after the event begins. (In the model's notation, the first hour of the event corresponds to HoursFromEvent aymh $_{1}=0$.) We include 10 lead terms and 17 contemporaneous/lag terms, which is all possible leading/lagging indicators given

\footnotetext{
${ }^{31}$ Data available from ufc.com, by clicking "events" followed by "all events" followed by "past." Our sample includes UFC 117 to UFC 207, retrieved on 26 Nov 2016.

${ }^{32}$ Similar to our main analysis we transform counts using the inverse hyperbolic sine transformation to address the fact that the number of crimes are zero in many agency-hours, making the natural log undefined. As such, the outcome variable is $\ln \left(\frac{\text { count }+\sqrt{\text { count }^{2}+1}}{\text { population }}\right)$.
} 
the data and time zones represented therein. ${ }^{33}$ The agency-by-year fixed effects, $\theta_{a y}$, capture differences across agencies that vary year by year; agency-by-month fixed effects, $\delta_{a m}$, address seasonality in crime rates specific to each agency; state-by-hour fixed effects, $\gamma_{s h}$, address the potential for crime to vary across hours of the day in a given state; and $\epsilon_{a t}$ are random error terms that we allow to be correlated across time for each agency. Given this specification, the estimated effects are identified through within-agency comparisons of hourly patterns of crime leading up to and following UFC events on event-day Saturdays to the patterns on non-event Saturdays, after controlling for agency-specific differences across months and years, and state-specific hours of the day.

The results of this analysis are shown in Figure 7, with Panel A showing estimated effects on assaults and Panel B showing the estimated effects on assaults in bars. Notably, the estimated effects are generally close to zero for all of the hours leading up to UFC main events. We also do not find any evidence of effects five-to-seven hours after events begin airing. Notably, the one statistically significant effect that we find for assaults (Panel A) is in the hour after the event has begun airing - this estimate indicates a 1.7 percent reduction in assaults. The estimated effect on assault is in the second hour after the event has begun airing is statistically significant at the 10 -percent level, indicating a 0.1 percent reduction in assaults. For assaults in bars (Panel B), the one statistically significant effect that we find is in the second hour after the event has begun airing - this estimate indicates a 0.1 percent reduction in assaults in bars. The point estimates are just a bit smaller in magnitude in the third and fourth hours after the event begins airing, though these estimates are not statistically significant at conventional levels. ${ }^{34}$ As a whole, this set of estimates provides

\footnotetext{
${ }^{33}$ We do not report the estimates for the earliest (latest) lead (lag) terms, which have very large standard errors because they are only identified off of a subset of the data in the latest (earliest) time zones.

${ }^{34}$ Normal bouts consist of three five-minute rounds for a maximum fight time of 15 minutes and maximum event time of 17 minutes inclusive of two one-minute recoveries. Championship and non main-event bouts are each five, five-minutes rounds, for a maximum fight time of 25 minutes and maximum event time of 29 minutes inclusive of recovery times. At ten-to-eleven bouts per event, if half of those are normal bouts, and all bouts go their limit, an event is four hours in length plus whatever time is afforded in transitions from one fight to the next. Many bouts do not go their full allotment of rounds, however, and to the extent this is the case, four hours would be somewhat higher than the average time over which fights were experienced. That said, pre-fight and post-fight interviews are also packaged into events, so the entire event can last upwards of
} 
support for the idea that the sort of content featured on TUF reduces violent crime.

\section{Conclusion}

We provide the first causal estimates demonstrating persistent effects of violent media content on violent behavior. Our estimation strategy relies on the fact that people tend to exhibit habit persistence in television viewing, which causes some individuals to watch TUF when it begins airing. Intuitively, we estimate the effects by comparing counties where individuals watch the same amount of Spike TV in 2004 overall, but vary in the amount of viewership in TUF's future time slot.

Our results indicate that viewership of TUF's first season significantly reduced violence, in the months the show first premiered and for many years thereafter. These reductions are driven by the category one might anticipate being responsive (given that TUF features sanctioned assaults, in some sense) and not by those that might constitute a stretch (i.e., murder). In support of our causal interpretation of these estimates, we find estimates very close to zero in "placebo tests" for effects prior to TUF's premier. We also demonstrate short-term responsiveness to mixed martial arts events depicting similar content that air in bars and on Pay-Per-View, which we also interpret as supportive of our causal interpretation.

We believe that it is particularly informative that our results reinforce the findings of prior well-identified field studies (Dahl and DellaVigna, 2009; Markey et al., 2015; Cunningham et al., 2016), because our study is unique in evaluating effects of a "treatment" that involves repeated exposure to violent media content. Taken literally, this evidence suggest that violent media content may be a part of the solution to societal violence, and not a factor contributing to the problem. Less ambitiously, our read of the evidence must at least suggest that violent media content is not necessarily harmful in the short run or, now, in the long run.

It's also worth noting that the magnitude and the persistence of the reductions in crime documented in our analysis suggest that there must be more to the mechanisms observed six hours. 
in real life than mechanically induced incapacitation effects resulting from initial exposure. Moreover, we would emphasize that a careful interpretation of these effects requires one to consider how that initial exposure might affect individuals' future activities. Considering the popularity of the UFC, and the role played by TUF in igniting that popularity, we believe that "follow-on incapacitation effects" are a likely channel through which we are finding such large and persistent effects on violent behavior. While we cannot rule out potential psychological effects regarding the way that individuals' think about the desirability of engaging in anti-social behavior - that the popularity of UFC grew so much following TUF's premier suggests that the long-run effects we find could be explained by follow-on incapacitation effects. Indeed, the empirical regularities we document are consistent with escalating interest in TUF-induced, UFC-related activities that displace other activities during which crimes would have been more likely to be committed. The effects of early exposure to TUF that we identify eventually fade out (after roughly five years), which is consistent with widespread UFC-popularity eventually leaving little difference between those who were exposed to UFC early and the broader population.

Given the current body of evidence, we think it appropriate to suggest caution in making any strong policy prescriptions one way or the other. We should certainly be more skeptical about policy prescriptions based on the wealth of laboratory-based studies, given that the short-run effects that might be expected from those studies have not been found in rigorous studies of individuals in their natural environments. In terms of the long-run causal effects, having introduced the first-such estimates to the literature - from the lab or the natural environment - we believe it is important to recognize that we provide but one data point that speaks to a very complicated question involving the effects of a diverse set of content that is typically lumped together as "violent media content." It will be critical for future research to try to understand whether violent media content is violent crime-reducing in general or whether there is something peculiar about the content we examine. 


\section{References}

Abadie, Alberto, Susan Athey, Guido Imbens, and Jeffrey Wooldridge. 2020. "Sampling-based vs. Design-based Uncertainty in Regression Analysis." Econometrica, 88.

Abadie, Alberto, Alexis Diamond, and Jens Hainmueller. 2015. "Comparative Politics and the Synthetic Control Method." American Journal of Political Science, 59(2): $495-510$.

Anderson, C. A., A. Shibuya, N. Ihori, E.L. Swing, B.J. Bushman, A. Sakamoto, H. R. Rothstein, and Muniba Saleemand. 2010. "Violent Video Game Effects on Aggression, Empathy, and Prosocial Behavior in Eastern and Western Countries: A Meta-Analytic Review." Psychological Bulletin, 136(2): 151-173.

Anderson, Craig A., Leonard Berkowitz, Edward Donnerstein, L. Rowell Huesmann, James D. Johnson, Daniel Linz, Neil M. Malamuth, and Ellen Wartella. 2003. "The Influence of Media Violence on Youth." Psychological Science in the Public Interest, 4(3): 81-110.

Bandura, Albert. 1977. Social Learning Theory. Oxford, England: Prentice-Hall.

Baumeister, Roy F., and Todd F. Heatherton. 1996. "Self-Regulation Failure: An Overview." Psychological Inquiry, 7(1): 1-15.

Becker, Gary S. 1968. "Crime and Punishment: An Economic Approach." Journal of Political Economy, 76(2): 169-217.

Bhuller, Manudeep, Tarjei Havnes, Edwin Leuven, and Magne Mogstad. 2013. "Broadband Internet: An Information Superhighway to Sex Crime?" Review of Economic Studies, 80(4): 1237-1266.

Bushman, Brad J., and Craig A. Anderson. 2015. "Understanding Causality in the Effects of Media Violence." American Behavioral Scientist, 59(14): 1807-1821.

Card, David, and Gordon B. Dahl. 2011. "Family Violence and Football: The Effect of Unexpected Emotional Cues on Violent Behavior." The Quarterly Journal of Economics, 126(1): 103-143, URL: https://ideas.repec.org/a/oup/qjecon/v126y2011i1p103-143.html.

Cornelson, Kirsten. 2018. "Media Role Models and Black Educational Attainment: Evidence from The Cosby Show." Mimeo.

Cunningham, Scott, Benjamin Engelstätter, and Michael R. Ward. 2016. "Violent Video Games and Violent Crime." Southern Economic Journal, 82(4): 1247-1265.

Dahl, Gordon, and Stefano DellaVigna. 2009. "Does Movie Violence Increase Violent Crime?" The Quarterly Journal of Economics, 124(2): 677-734.

DellaVigna, Stefano, and Eliana La Ferrara. 2015. "Chapter 19 - Economic and Social Impacts of the Media." In Handbook of Media Economics. eds. by Simon P. Anderson, Joel Waldfogel, and David Strömberg: North-Holland, 723 - 768. 
Dollard, John, Neal E. Miller, Leonard W. Doob, O. H. Mowrer, and Robert R. Sears. 1939. Frustration and aggression.: Yale University Press, , DOI: http://dx.doi.org/ doi:10.1037/10022-000.

Donnerstein, E., M. Donnerstein, and R. Evans. 1975. "Erotic Stimuli and Aggression: Facilitation or Inhibition." Journal of Personality and Social Psychology, 32, p. 237-244.

Eron, L. D., L. R. Huesmann, M. M. Lefkowitz, and L. O. Walder. 1972. "Does Television Violence Cause Aggression?" American Psychologist, 27, p. 253-263.

Fiske, Alan Page, and Tage Shakti Rai. 2014. Virtuous Violence: Hurting and Killing to Create, Sustain, End, and Honor Social Relationships.: Cambridge University Press, , DOI: http://dx.doi.org/10.1017/CBO9781316104668.

Gentile, Douglas A, Paul J Lynch, Jennifer Ruh Linder, and David A Walsh. 2004. "The Effects of Violent Video Game Habits on Adolescent Hostility, Aggressive Behaviors, and School Performance." Journal of Adolescence, 27(1): 5 - 22, Video Games and Public Health.

Gentzkow, Matthew. 2006. "Television and Voter Turnout." The Quarterly Journal of Economics, 121(3): 931-972.

Gentzkow, Matthew, and Jesse M. Shapiro. 2008. "Preschool Television Viewing and Adolescent Test Scores: Historical Evidence from the Coleman Study." The Quarterly Journal of Economics, 123(1): 279-323.

Ginges, Jeremy, and Scott Atran. 2009. "What motivates participation in violent political action: selective incentives or parochial altruism?" Annals of the New York Academy of Sciences, 1167 115-23.

Greitemeyer, Tobias, and Dirk O. Mügge. 2014. "Video Games Do Affect Social Outcomes: A Meta-Analytic Review of the Effects of Violent and Prosocial Video Game Play." Personality and Social Psychology Bulletin, 40(5): 578-589.

Hasan, Youssef, Laurent Bègue, and Brad J. Bushman. 2013. "Violent Video Games Stress People Out and Make Them More Aggressive." Aggressive Behavior, 39(1): 64-70.

Heckman, James J., and V. Joseph Hotz. 1989. "Choosing Among Alternative Nonexperimental Methods for Estimating the Impact of Social Programs: The Case of Manpower Training." Journal of the American Statistical Association, 84(408): 862-874, URL: http://www.jstor.org/stable/2290059.

Jaeger, David A., Theodore J. Joyce, and Robert Kaestner. 2016. "Does Reality TV Induce Real Effects? On the Questionable Association Between 16 and Pregnant and Teenage Childbearing." IZA Discussion Papers 10317, Bonn.

Jaeger, David A., Theodore J. Joyce, and Robert Kaestner. 2020. "A Cautionary Tale of Evaluating Identifying Assumptions: Did Reality TV Really Cause a Decline in Teenage Childbearing?" Journal of Business 83 Economic Statistics, 38(2): 317-326. 
Johnson, Jeffrey G., Patricia Cohen, Elizabeth M. Smailes, Stephanie Kasen, and Judith S. Brook. 2002. "Television Viewing and Aggressive Behavior During Adolescence and Adulthood." Science, 295(5564): 2468-2471.

Josephson, W. L. 1987. "Television Violence and Children's Aggression: Testing the Priming, Social Script, and Disinhibition Predictions." Journal of Personality and Social Psychology, 53(5): 882-890.

Kahn-Lang, Ariella, and Kevin Lang. 2019. "The Promise and Pitfalls of Differences-inDifferences: Reflections on 16 and Pregnant and Other Applications." Journal of Business \& Economic Statistics, 0(0): 1-14.

Kearney, Melissa S., and Philip Levine. Forthcoming. "Early Childhood Education by Television: Lessons from Sesame Street." American Economic Journal: Applied Economics.

Kearney, Melissa S., and Phillip B. Levine. 2015. "Media Influences on Social Outcomes: The Impact of MTV's 16 and Pregnant on Teen Childbearing." American Economic Review, 105(12): 3597-3632.

Kearney, Melissa S., and Phillip B. Levine. 2016. "Does Reality TV Induce Real Effects? A Response to Jaeger, Joyce, and Kaestner (2016)." IZA Discussion Paper 10318.

La Ferrara, Eliana, Alberto Chong, and Suzanne Duryea. 2012. "Soap Operas and Fertility: Evidence from Brazil." American Economic Journal: Applied Economics, 4(4): $1-31$.

Markey, P. M., C.N. Markey, and J.E. French. 2015. "Violent Video Games and Real-World Violence: Rhetoric Versus Data." Psychology of Popular Media Culture, 4(4): $277-295$.

Parke, R D, L Berkowitz, J P Leyens, and S West. 1977. "Some Effects of Violent and Nonviolent Movies on the Behaviour of Juvenile Delinquents."

Posner, Richard A. 1992. Sex and Reason. Cambridge, MA: Harvard University Press.

Trudeau, Jennifer. 2016. "The Role of New Media on Teen Sexual Behaviors and Fertility Outcomes-The Case of 16 and Pregnant." Southern Economic Journal, 82(3): 975-1003.

Ward, Michael R., "Adolescent Video Game Playing and Fighting over the Long-term." Contemporary Economic Policy, n/a(n/a): .

Ward, Michael Robert. 2011. "Video Games and Crime." Contemporary Economic Policy, 29(2): 264-271. 
Figure 1

Ultimate Fighting Championship popularity over time

Panel A: As measured by total main event (PPV) buys

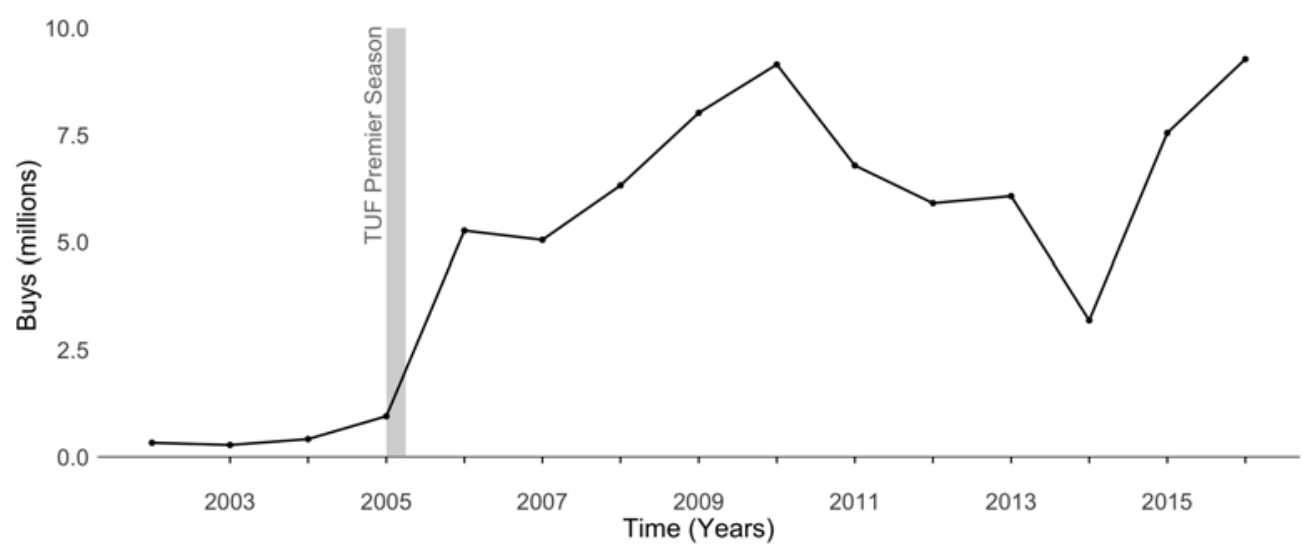

Panel B: As measured by "unrelated" Google searches

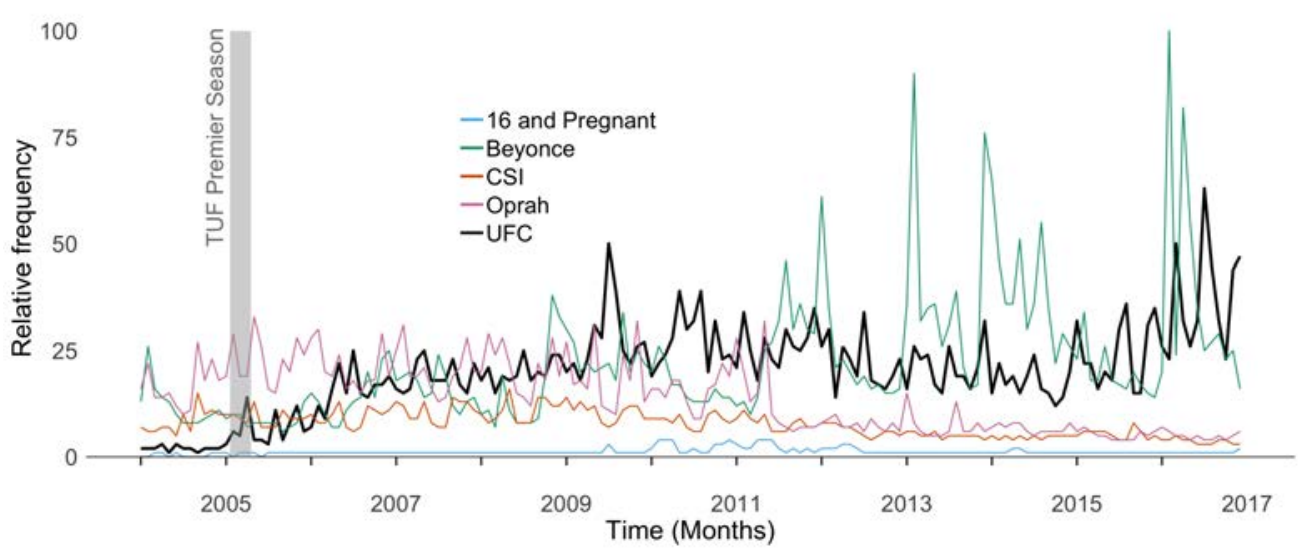

Panel C: As measured by "related" Google searches

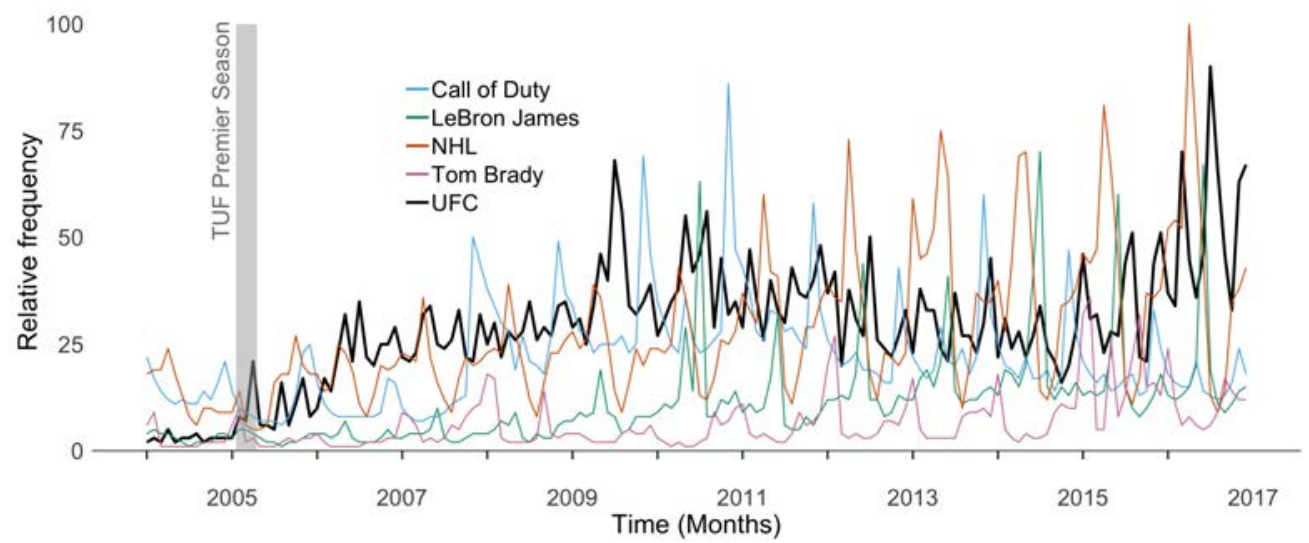

Notes: In Panel A, we plot the number of Pay-Per-View buys annually, available from https://thesportsdaily.com/2018/02/16/ all-time- ufc-ppv-sales-data-fox $11 /$. In panels B and C, we plot Google search results, which are always proportionate to the time and location of a query. (To be able to compare relative popularity, each data point is divided by the total searches of the geography and time range it represents. The resulting numbers are then scaled on a range of 0 to 100 based on a topic's proportion to all searches on all topics.) In our case, we requested data for all available months, but originating in thg 2 nited States. 
Figure 2

Graphical depiction of the first stage
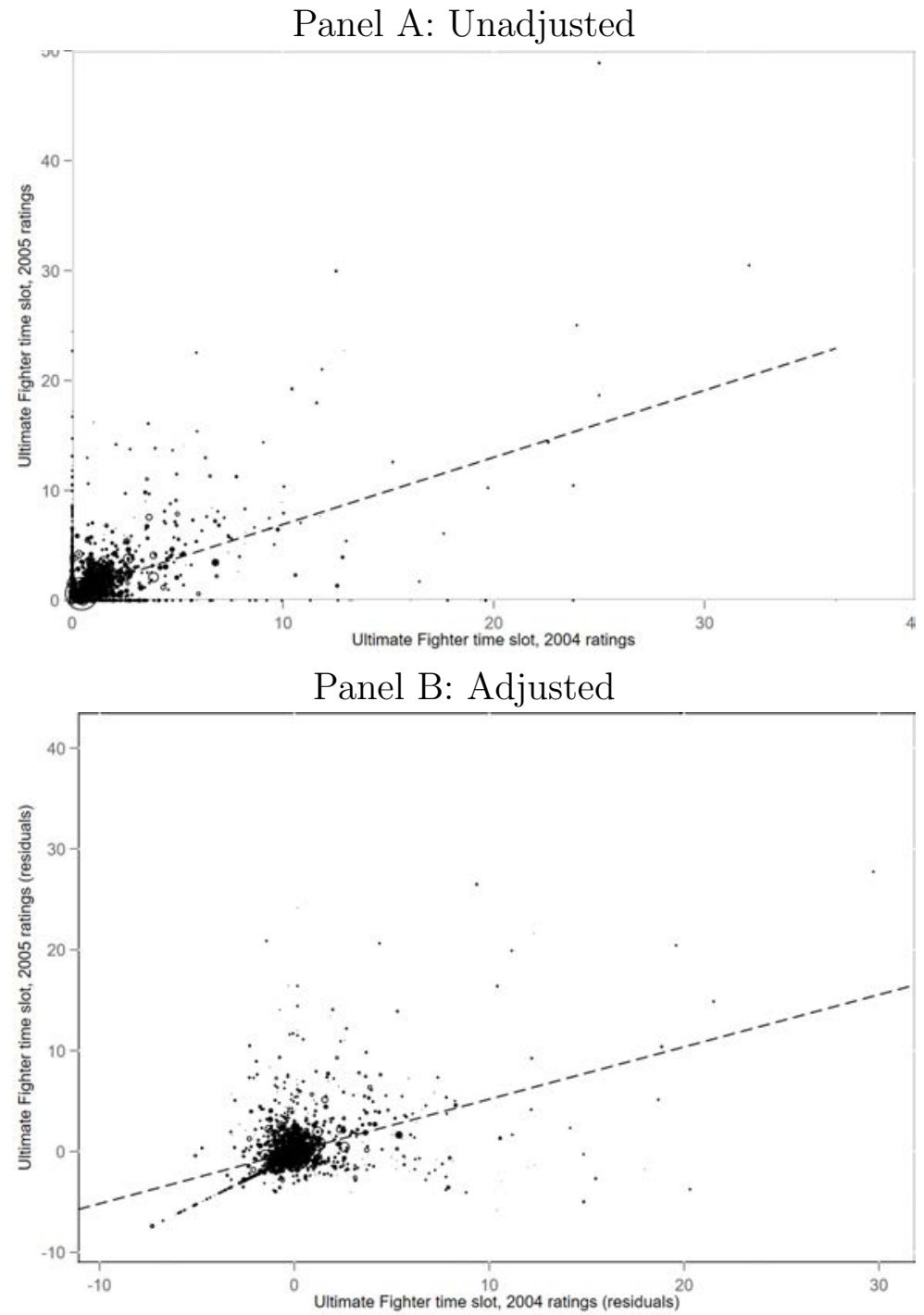

Notes: In this figure we plot Season 1 TUF ratings (February 2005) and Spike network ratings in the same time slot before TUF premiered (November 2004). The graph labeled "adjusted" plots the residuals of these ratings, each adjusted for overall Spike viewership before TUF premiered (November 2004). 
Figure 3

Viewership in The Ultimate Fighter's time slot (in 2004) before its premier (in 2005)

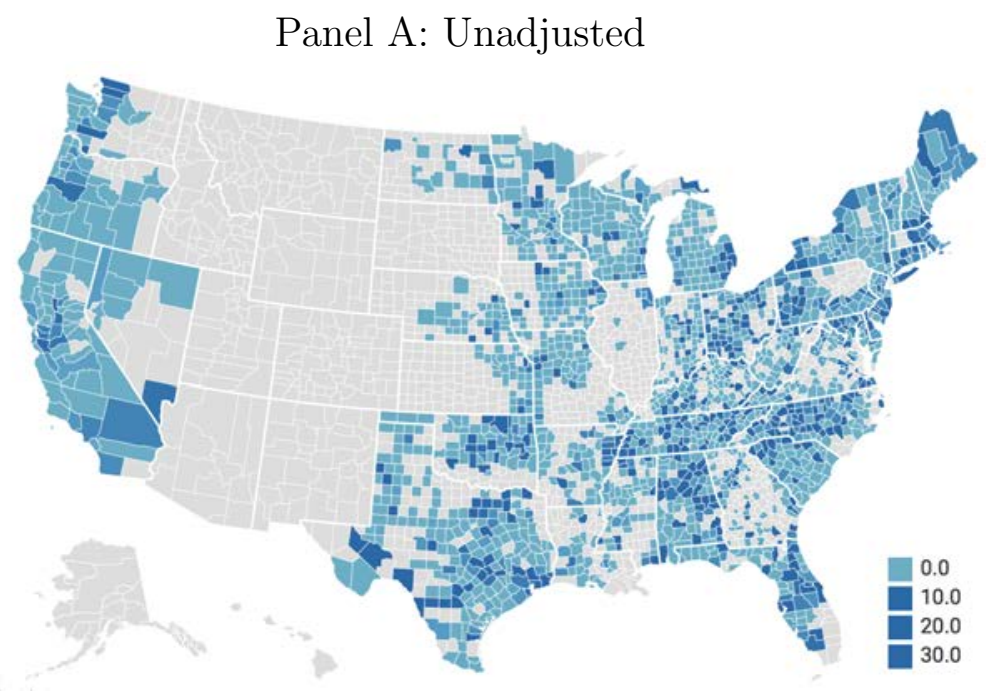

Panel B: Adjusted for overall Spike TV viewership (2004)

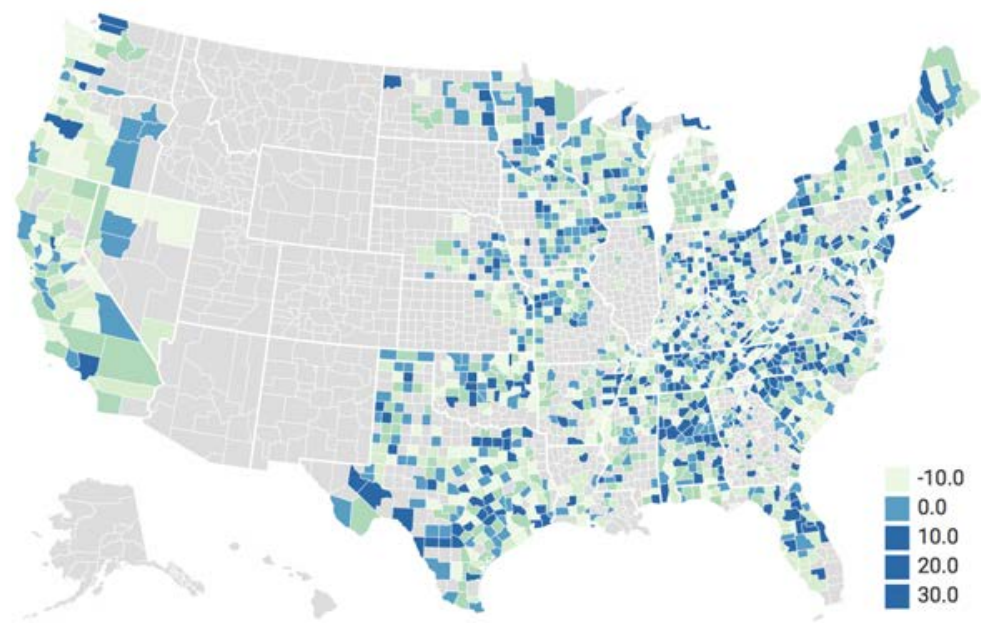

Notes: County-level ratings data from Nielsen. Spike TV Viewership in TUF's time slot is measured in November 2004. Season 1 TUF viewership is measured during February 2005. Overall Spike TV viewership is during November 2004. See Section 3 for additional details. 
Figure 4

How controlling for pre-treatment Spike TV overall ratings eliminates the links between the instrument and pre-treatment violent crime rate levels and trends

Panel A: 2004 log violent crime rates vs 2004 rating in TUF time slot
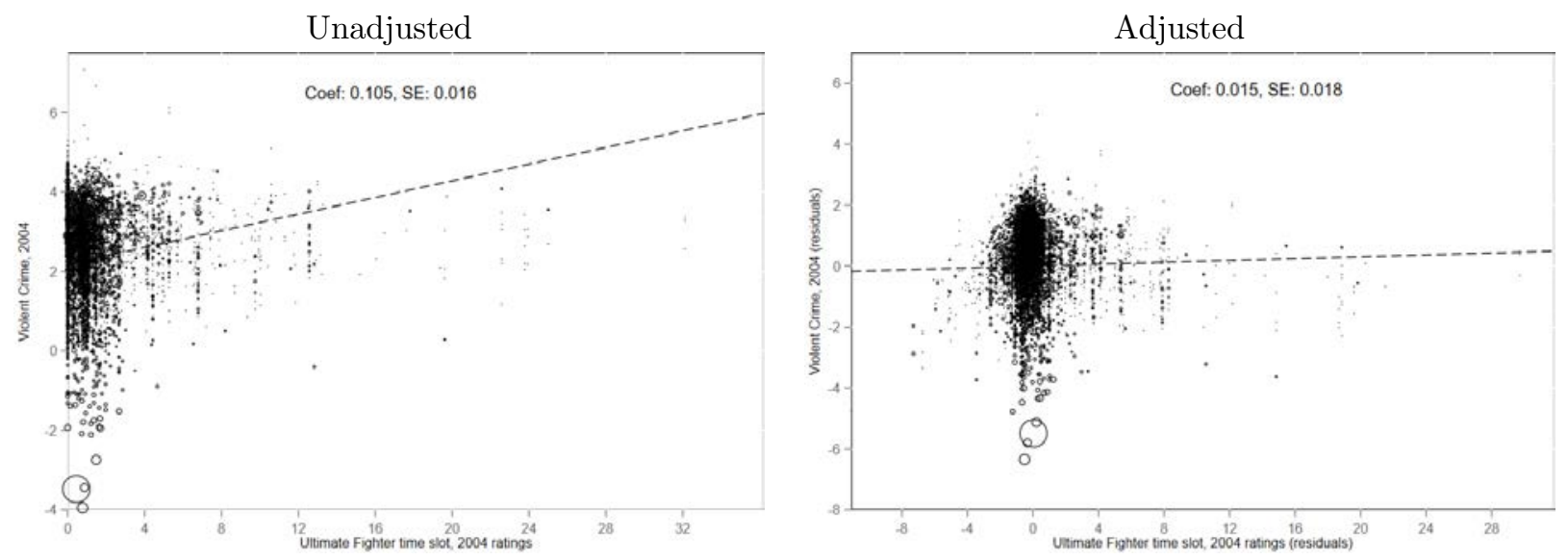

Panel B: 2001-2004 change in log violent crime rates vs 2004 rating in TUF time slot
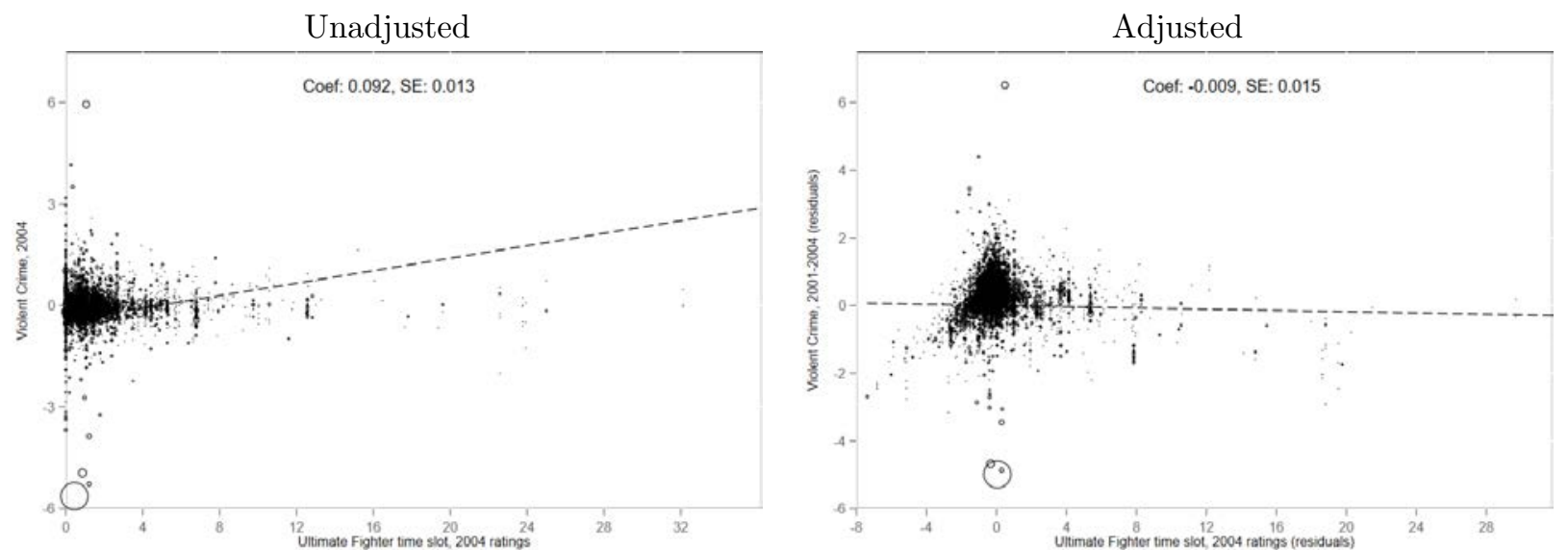

Notes: In Panel A, the "unadjusted" graphic plots the log of the violent crime rate in 2004 and The Ultimate Fighter time slot ratings in 2004 while the "adjusted" graphic plots the residuals from the log of the violent crime rate in 2004 and the Ultimate Fighter time slot ratings in 2004 both adjusted for overall Spike viewership in 2004. Panel B is similar but uses the 2001-2004 change in the log of the violent crime rate instead of the 2004 level. Each observations is weighted (indicated by size) by agency jurisdiction population. 
Figure 5

2SLS estimates of the effect of Season 1 TUF viewership on violent crimes

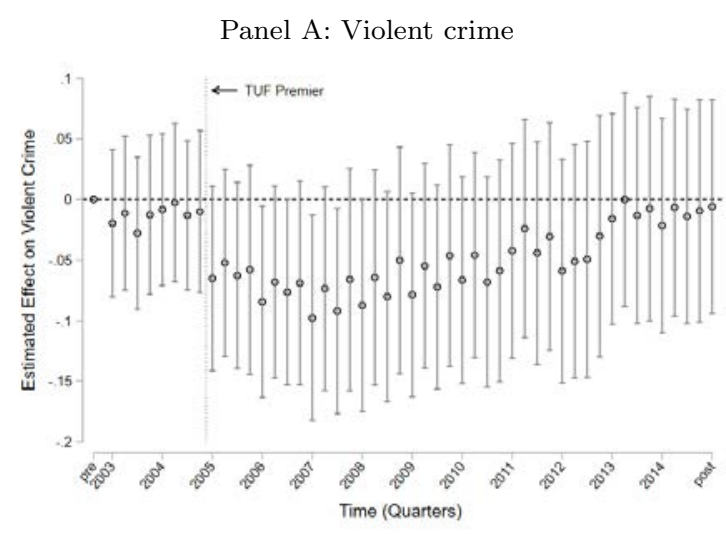

Panel C: Rape

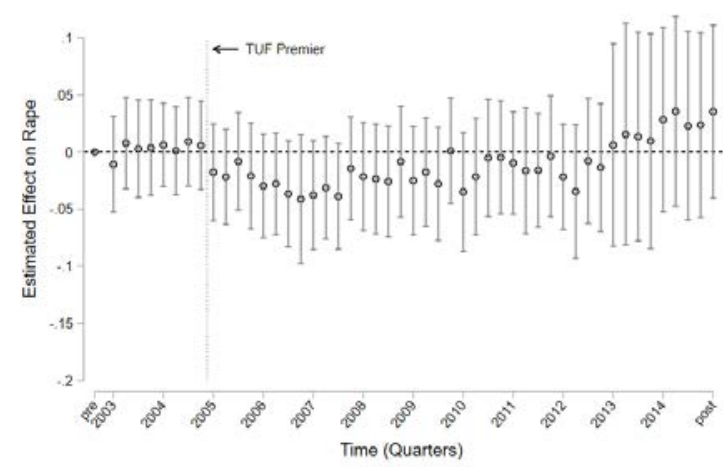

Panel B: Assault

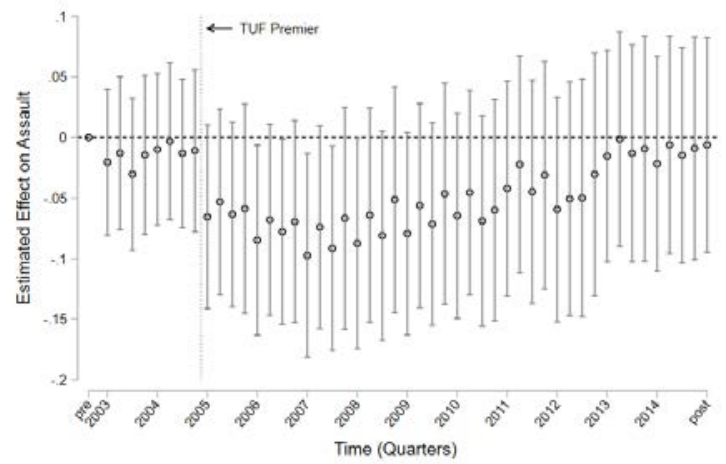

Panel D: Murder

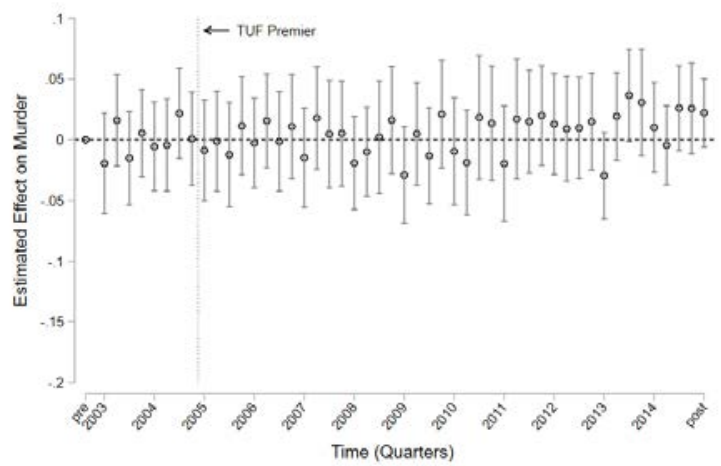

Notes: Estimates are based on 1,372,296 monthly observations spanning 2001-2016 for 8,750 law-enforcement agencies participating in the Uniform Crime Reports: Offenses Known Segment. The figure plots coefficients and 95 percent confidence intervals of quarter indicators interacted with average Ultimate Fighter viewership ratings from an instrumental variables model where the instrument is the 2004 viewership ratings for the the same time slot and network as TUF would air (in 2005). The outcome variable is the log of the number of reported offenses per 10,000 residents in the agency jurisdiction. The models include year-by-month and agency fixed effects. The regressions are weighted by agency jurisdiction population. Standard-error estimates allow for clusters at the county level. 
Figure 6

2SLS estimates of the effect of Season 1 TUF viewership on property crimes

Panel A: Property crime

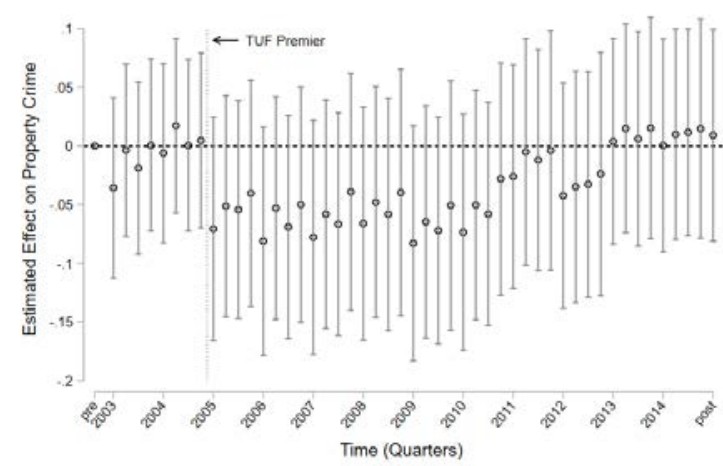

Panel C: Motor-Vehicle Theft

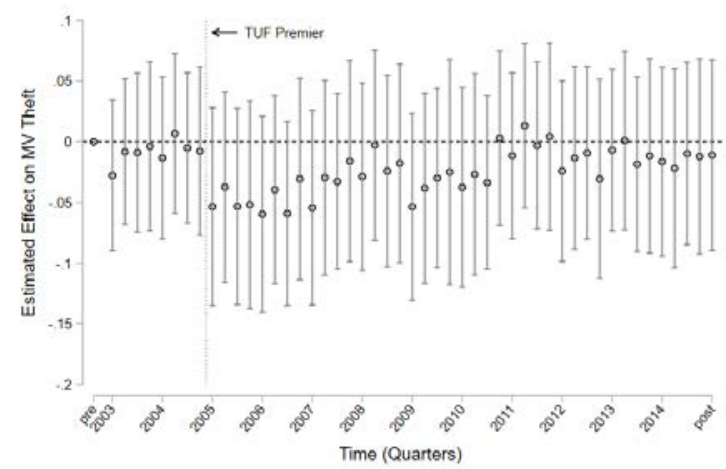

Panel B: Theft

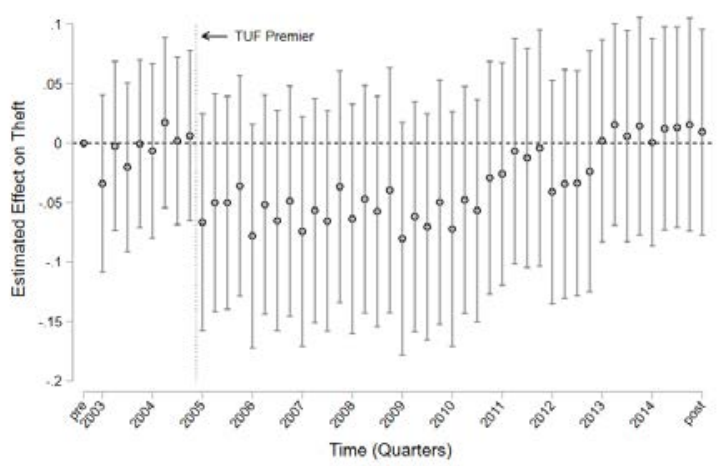

Panel D: Robbery

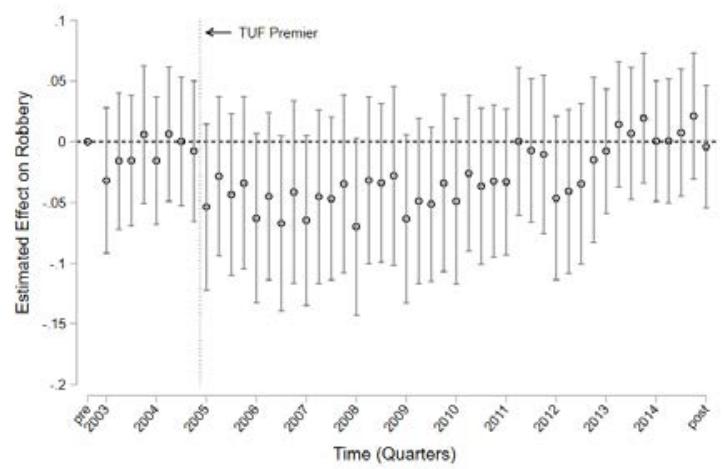

Notes: See Figure 5. 
Figure 7

Estimated effects of UFC "Pay-Per-View Main Events"

Panel A: Assault

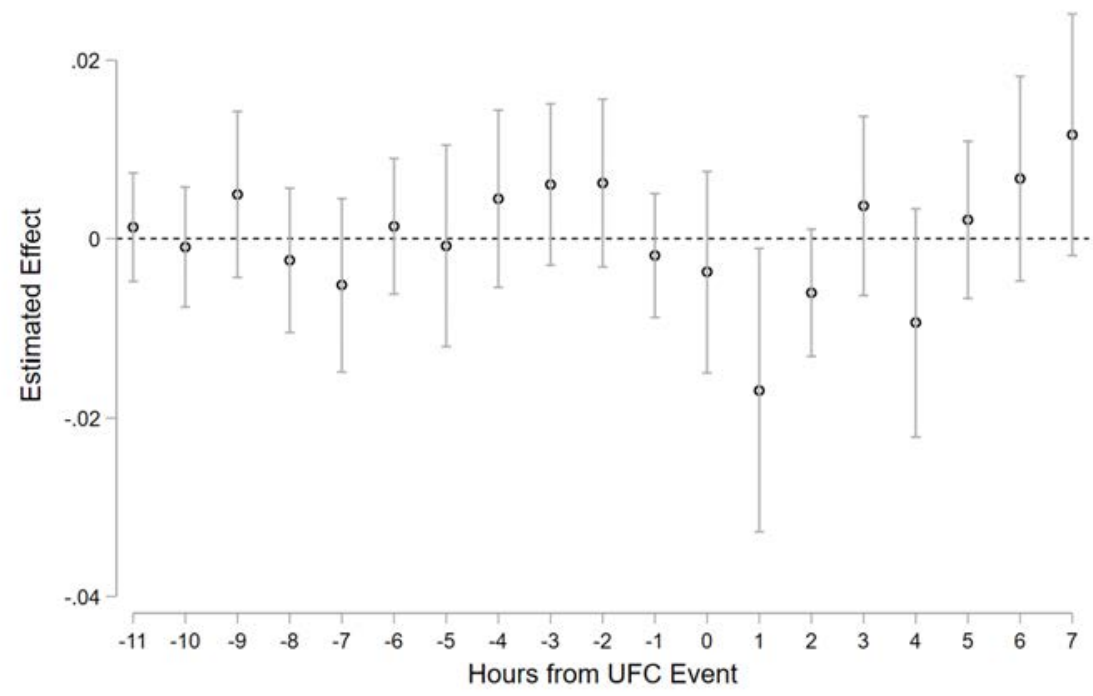

Panel B: Assault in bars

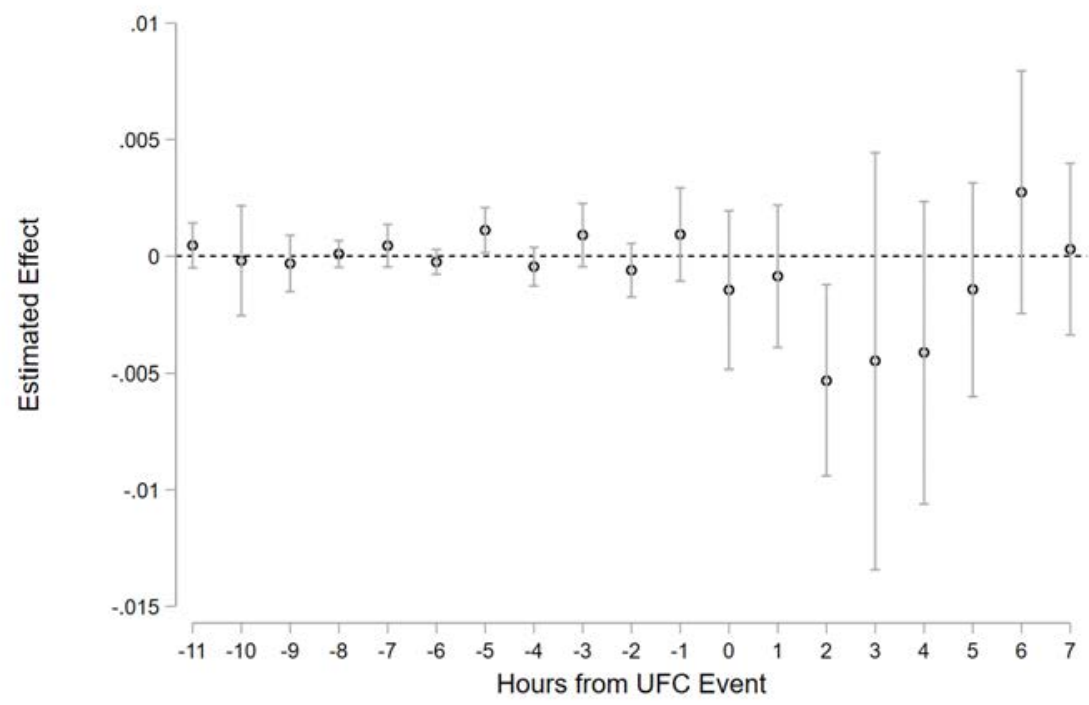

Notes: Estimates are based on 15,144,168 hourly observations on Saturdays spanning 2010-2015 for 3,771 municipal law-enforcement agencies participating in the FBI's National Incident Based Reporting System (NIBRS). The figure plots coefficients and 95 percent confidence intervals of hourly indicators leading up to and following the start of Pay-Per-View UFC Events. The outcome variable is the log of the number of reported offenses per 10,000 residents in the agency jurisdiction. The models include agency-by-month, agency-by-year, and state-by-hour fixed effects. The regressions are weighted by agency jurisdiction population. Standard errors are clustered at the agency level. 
Table 1

Summary statistics for UCR and Nielsen Ratings data

\begin{tabular}{lc}
\hline \hline & \\
Violent Crime & 11.33 \\
Assault & 11.01 \\
Rape & 0.27 \\
Murder & 0.05 \\
Property Crime & 30.34 \\
Theft & 25.71 \\
Motor-Vehicle Theft & 3.15 \\
Robbery & 1.48 \\
Ultimate Fighter time slot, 2005 ratings & 1.59 \\
Ultimate Fighter time slot, 2004 ratings & 1.06 \\
Ultimate Fighter network, 2004 ratings & 0.36 \\
& \\
Number of Agencies & 8,750 \\
N & $1,372,296$ \\
& \\
\hline \hline & Notes: Means of crime outcomes are the number of reported \\
offenses per 10,000 residents in the agency jurisdiction.
\end{tabular}


Table 2

First-stage estimates for The Ultimate Fighter ratings

\begin{tabular}{|c|c|c|}
\hline & $(1)$ & $(2)$ \\
\hline Ultimate Fighter time slot, 2004 ratings & $\begin{array}{c}0.616^{* * *} \\
(0.084)\end{array}$ & $\begin{array}{c}0.523^{* * *} \\
(0.082)\end{array}$ \\
\hline Ultimate Fighter network, 2004 ratings & & $\begin{array}{c}1.458^{* * *} \\
(0.370)\end{array}$ \\
\hline $\mathrm{F}$ & 53.76 & 40.68 \\
\hline $\mathrm{N}$ & $1,372,296$ & $1,372,296$ \\
\hline
\end{tabular}

Notes: Observations are at the agency-level to be consistent with our analysis of crime outcomes. Ratings are measured at the countylevel. The regressions are weighted by agency jurisdiction population. Standard-error estimates allow for clusters at the county level. The reported F-statistic is for the exclusion of 2004 ratings in The Ultimate Fighter's future time slot. *, **, and ***, indicate statistical significance at the ten-, five-, and one-percent levels, respectively. 
Table 3

2SLS estimates of the effect of Season 1 TUF viewership

\begin{tabular}{|c|c|c|c|c|}
\hline & \multicolumn{4}{|c|}{ Panel A: Violent crimes } \\
\hline & $\begin{array}{c}\text { Violent Crime } \\
\text { (1) }\end{array}$ & $\begin{array}{c}\text { Assault } \\
(2)\end{array}$ & $\begin{array}{c}\text { Rape } \\
(3)\end{array}$ & $\begin{array}{c}\text { Murder } \\
\text { (4) }\end{array}$ \\
\hline 2005-to-2009 × RateTUF 05 & $\begin{array}{c}-0.0636^{* *} \\
(0.0318)\end{array}$ & $\begin{array}{c}-0.0633^{* *} \\
(0.0316)\end{array}$ & $\begin{array}{c}-0.0257^{*} \\
(0.0150)\end{array}$ & $\begin{array}{l}-0.0002 \\
(0.0110)\end{array}$ \\
\hline Post $2009 \times$ RateTUF 05 & $\begin{array}{l}-0.0193 \\
(0.0389)\end{array}$ & $\begin{array}{l}-0.0188 \\
(0.0389)\end{array}$ & $\begin{array}{c}0.0063 \\
(0.0268)\end{array}$ & $\begin{array}{c}0.0131 \\
(0.0112)\end{array}$ \\
\hline Agencies & 8,750 & 8,750 & 8,750 & 8,750 \\
\hline $\mathrm{N}$ & $1,372,296$ & $1,372,296$ & $1,372,296$ & $1,372,296$ \\
\hline
\end{tabular}

Panel B: Property crimes

Property Crime Theft MV Theft Robbery

\begin{tabular}{lcccc} 
& $(1)$ & $(2)$ & $(3)$ & $(4)$ \\
\cline { 2 - 5 } 2005-to-2009 × RateTUF05 & -0.0575 & -0.0556 & -0.0327 & $-0.0420^{*}$ \\
& $(0.0400)$ & $(0.0389)$ & $(0.0303)$ & $(0.0255)$ \\
Post2009 $\times$ RateTUF05 & -0.0070 & -0.0069 & -0.0086 & -0.0067 \\
& $(0.0411)$ & $(0.0394)$ & $(0.0332)$ & $(0.0218)$ \\
Agencies & 8,750 & 8,750 & 8,750 & 8,750 \\
$\mathrm{~N}$ & $1,372,296$ & $1,372,296$ & $1,372,296$ & $1,372,296$ \\
& & & & \\
\hline
\end{tabular}

Notes: Estimates are based on monthly crime reports for law-enforcement agencies participating in the Uniform Crime Reports: Offenses Known Segment. Estimated coefficients are from an instrumental variables model where the instrument for average Ultimate Fighter viewership ratings is the 2004 viewership ratings for the the same time slot and network as TUF. The outcome variable is the log of the number of reported offenses per 10,000 residents in the agency jurisdiction. The models include year-by-month and agency fixed effects. The regressions are weighted by agency jurisdiction population. Standard-error estimates allow for clusters at the county level. ${ }^{*}, * *$, and ${ }^{* * *}$, indicate statistical significance at the ten-, five-, and one-percent levels, respectively. 
$7 \quad$ Appendix 


\section{Figure A1}

2SLS estimates: Robustness to time-varying county covariates

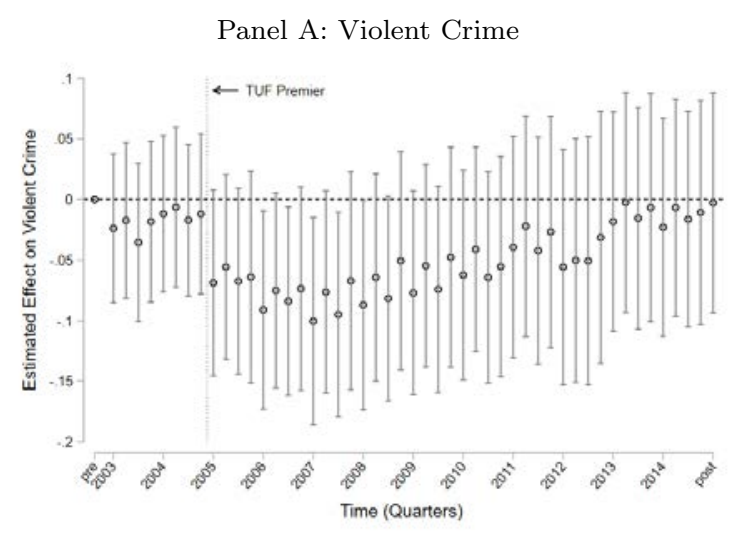

Panel C: Rape

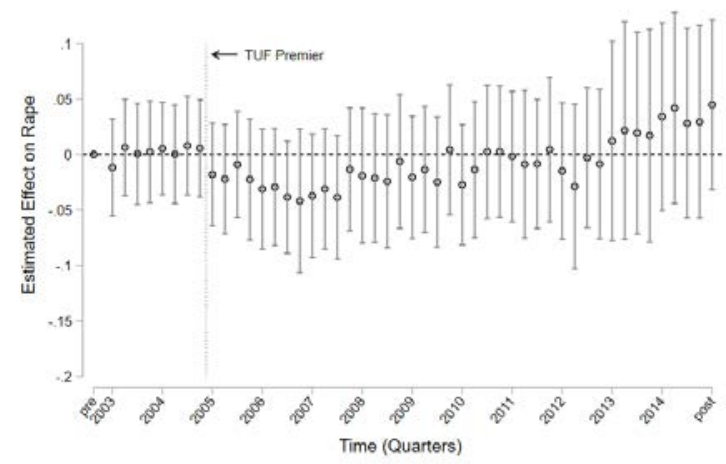

Panel B: Assault

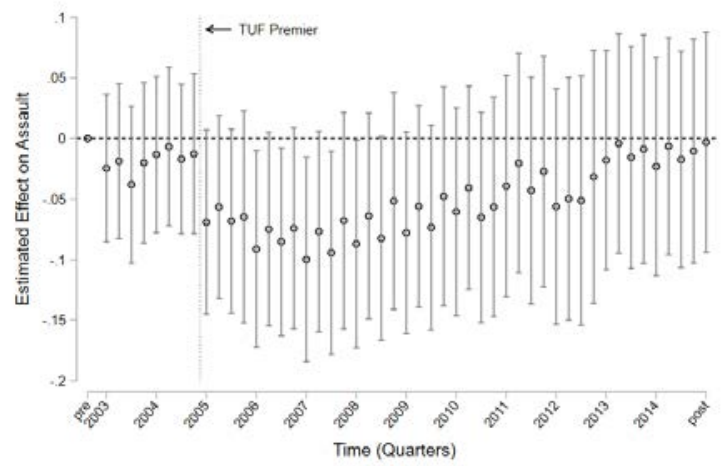

Panel D: Murder

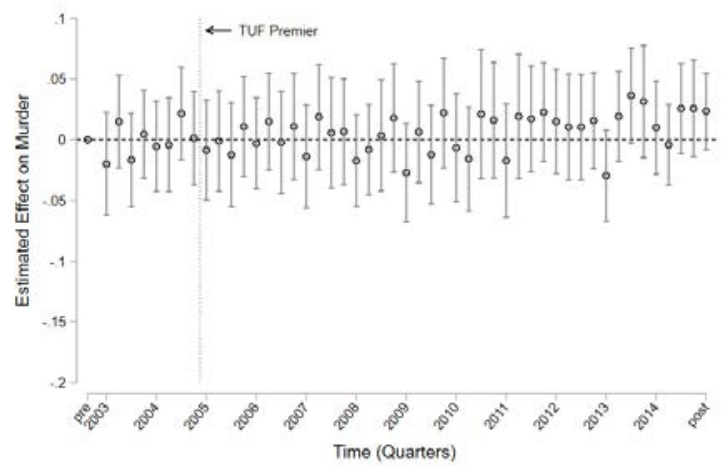

Notes: This figure is the same as Figure 5, except here the estimates are based on a model that additionally controls for the unemployment rate (measured at the county-month level) and for the following demographics (measured at the county-year level): percent white, percent black, percent hispanic, percent 0-12 years old, percent 13-17 years old, percent 18-22 years old, percent 23-27 years old, percent 28-40 years old, and percent $41+$ years old. 


\section{Figure A2}

2SLS estimates: Robustness to time-varying county covariates

Panel A: Property Crime

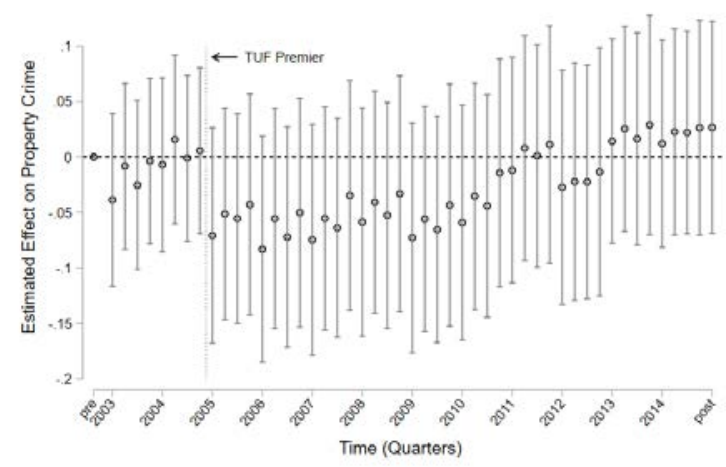

Panel C: Motor-Vehicle Theft

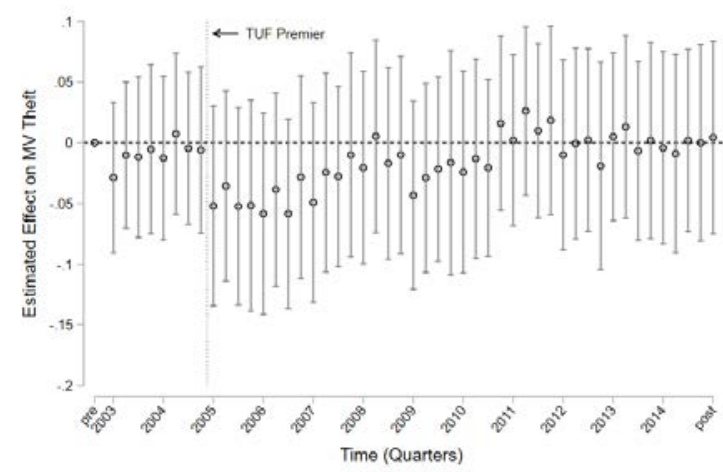

Panel B: Theft

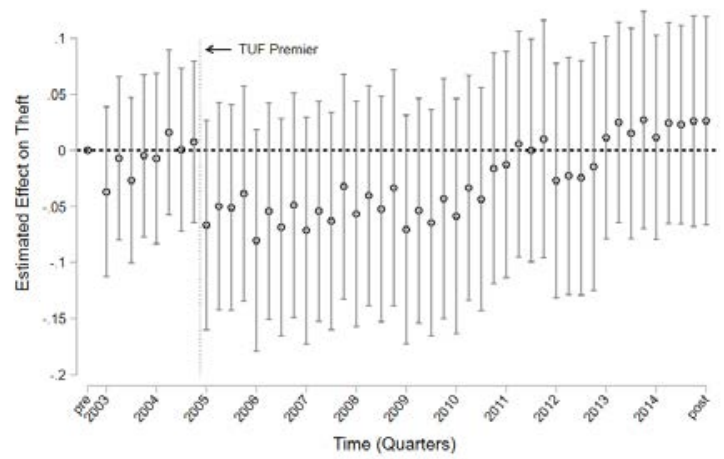

Panel D: Robbery

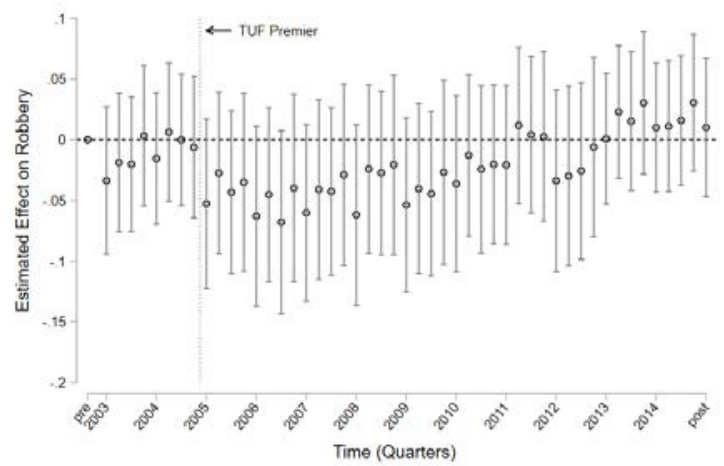

Notes: This figure is the same as Figure 6, except here the estimates are based on a model that additionally controls for the unemployment rate (measured at the county-month level) and for the following demographics (measured at the county-year level): percent white, percent black, percent hispanic, percent 0-12 years old, percent 13-17 years old, percent 18-22 years old, percent 23-27 years old, percent 28-40 years old, and percent $41+$ years old. 


\section{Figure A3}

2SLS estimates: Robustness to using the adjusted natural log the outcomes

Panel A: Violent crime

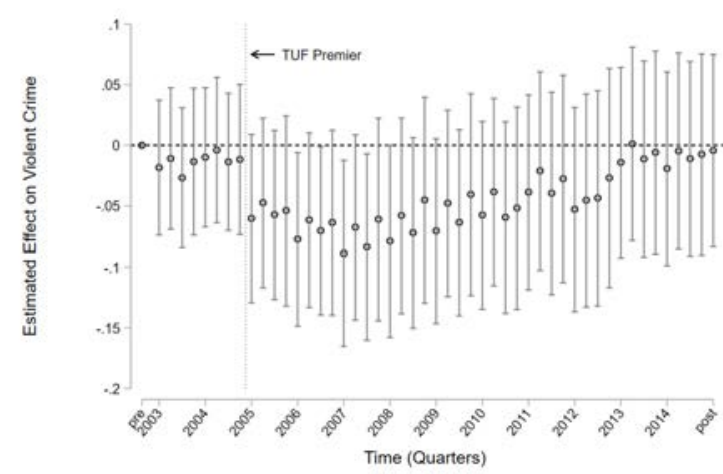

Panel C: Rape

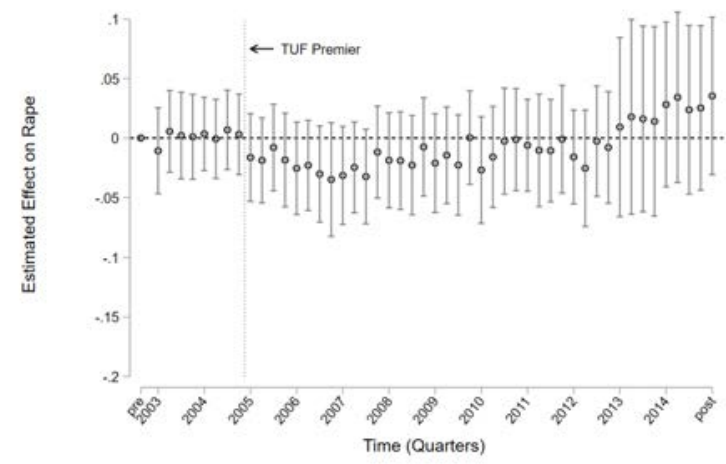

Panel B: Assault

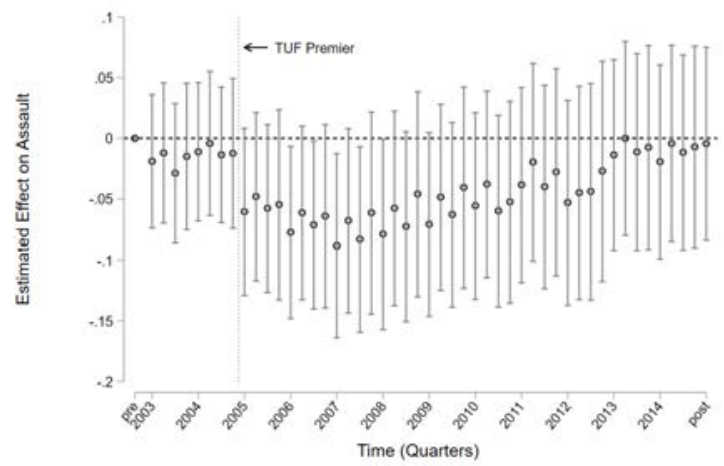

Panel D: Murder

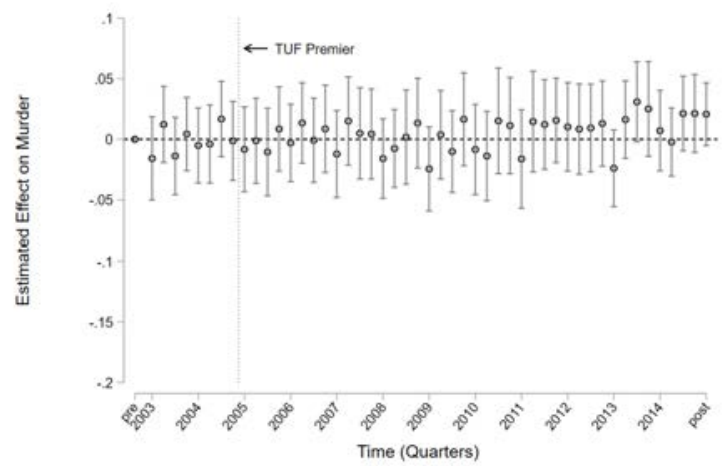

Notes: Estimates are based on 1,372,296 monthly observations spanning 2001-2016 for 8,750 law-enforcement agencies participating in the Uniform Crime Reports: Offenses Known Segment. The figure plots coefficients and 95 percent confidence intervals of quarter indicators interacted with average Ultimate Fighter viewership ratings from an instrumental variables model where the instrument is the 2004 viewership ratings for the the same time slot and network as TUF would air (in 2005). The outcome variable is the natural log plus one of the number of reported offenses per 10,000 residents in the agency jurisdiction. The models include year-by-month and agency fixed effects. The regressions are weighted by agency jurisdiction population. Standard-error estimates allow for clusters at the county level. 


\section{Figure A4}

2SLS estimates: Robustness to using the adjusted natural log of the outcomes

Panel A: Property crime

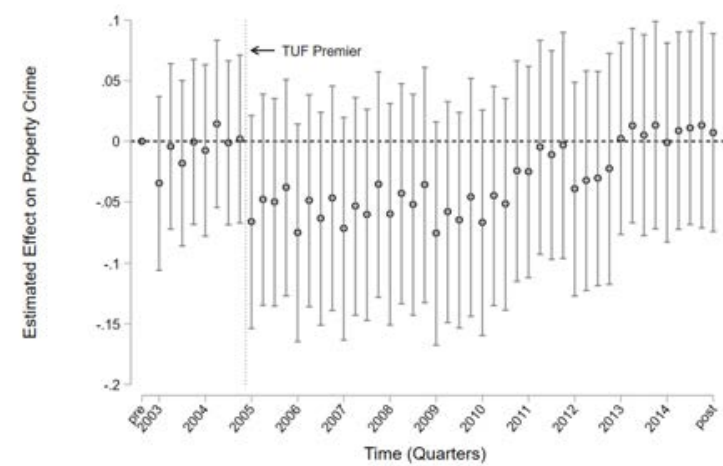

Panel C: Motor-Vehicle Theft

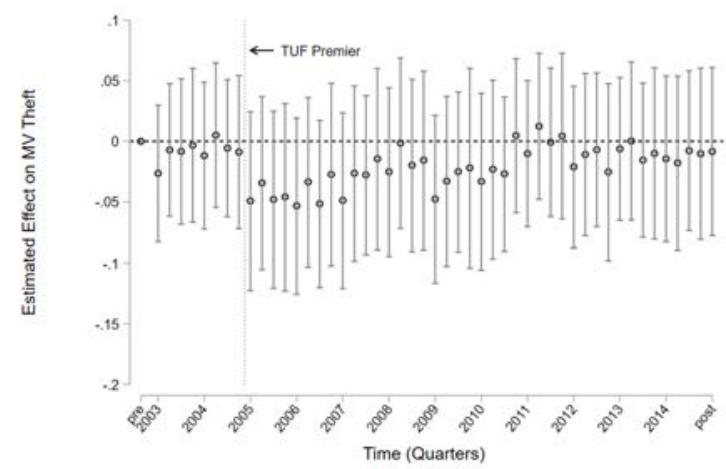

Panel B: Theft

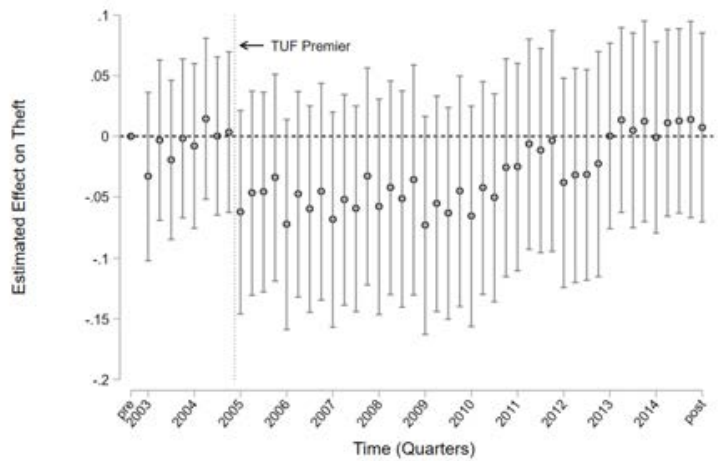

Panel D: Robbery

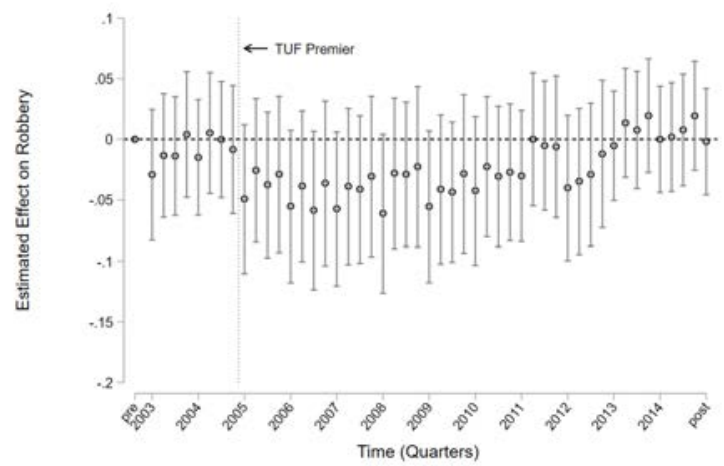

Notes: See Figure A3. 


\section{Figure A5}

2SLS estimates: Robustness to using the quartic root of the outcomes
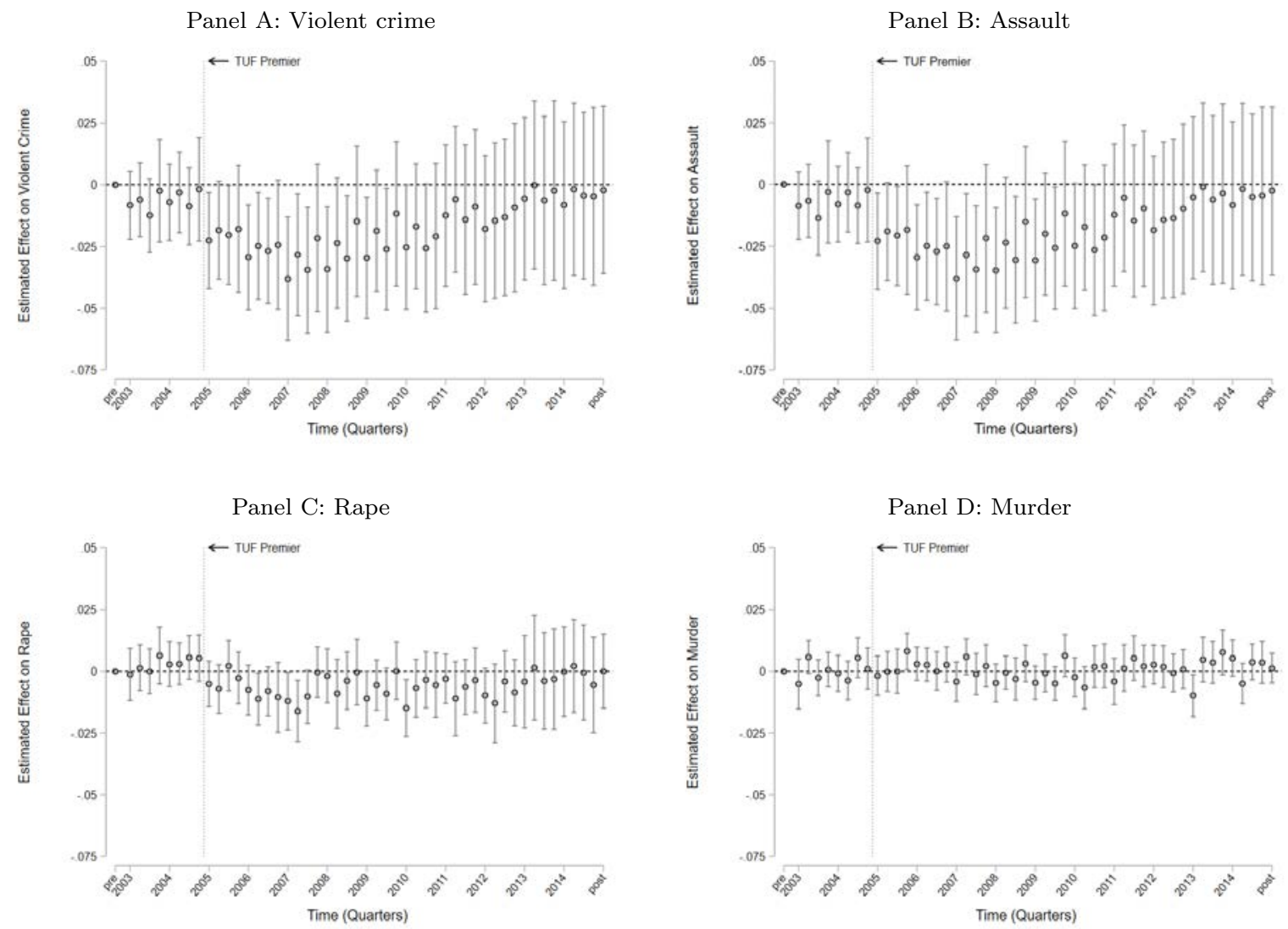

Notes: Estimates are based on 1,372,296 monthly observations spanning 2001-2016 for 8,750 law-enforcement agencies participating in the Uniform Crime Reports: Offenses Known Segment. The figure plots coefficients and 95 percent confidence intervals of quarter indicators interacted with average Ultimate Fighter viewership ratings from an instrumental variables model where the instrument is the 2004 viewership ratings for the the same time slot and network as TUF would air (in 2005). The outcome variable is the quartic root of the number of reported offenses per 10,000 residents in the agency jurisdiction. The models include year-by-month and agency fixed effects. The regressions are weighted by agency jurisdiction population. Standard-error estimates allow for clusters at the county level. 


\section{Figure A6}

2SLS estimate: Robustness to using the quartic root of the outcomes
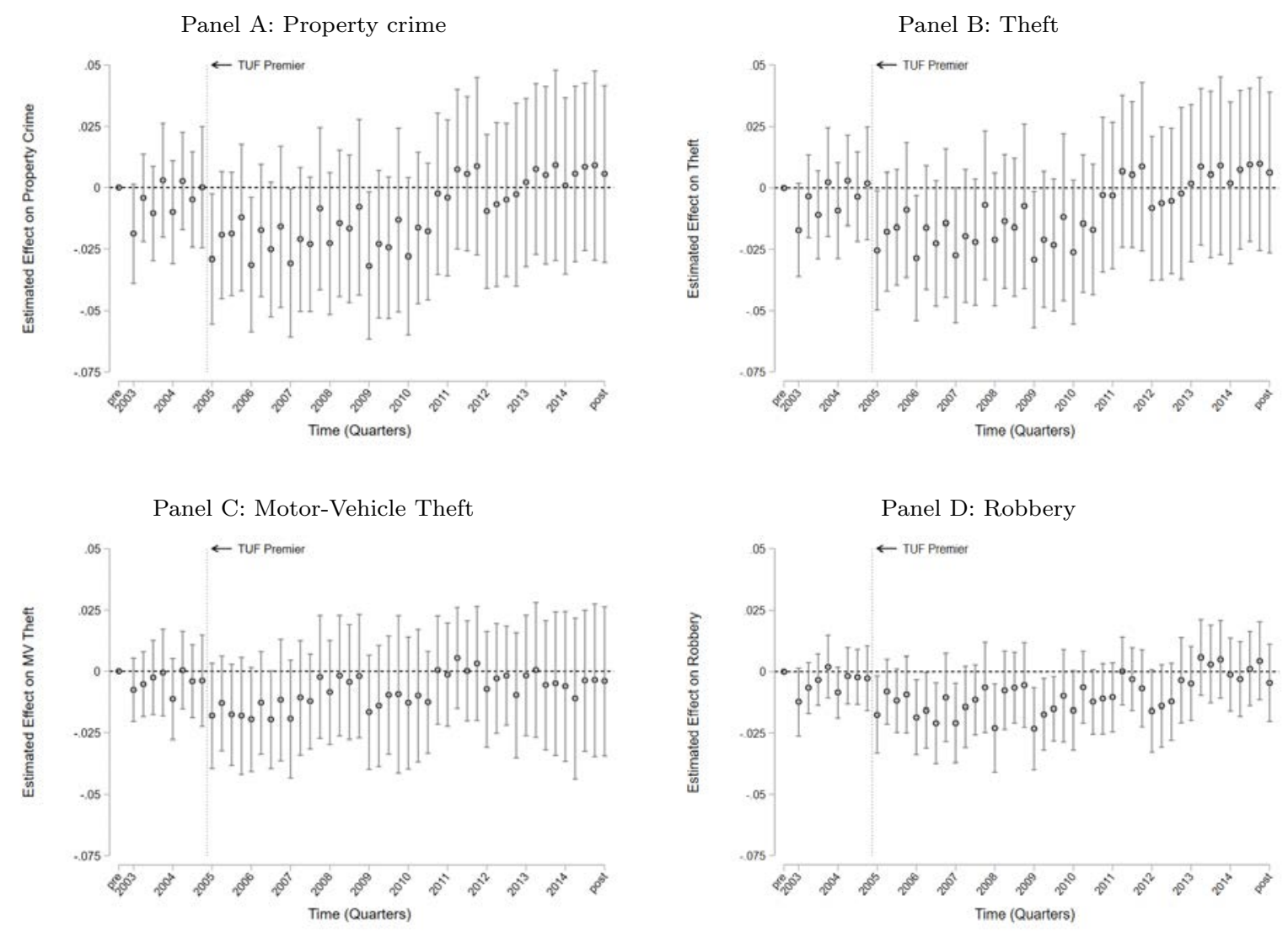

Notes: See Figure A5. 


\section{Figure A7}

Reduced-form estimates of the effect of 2004 viewership ratings on violent crimes over time
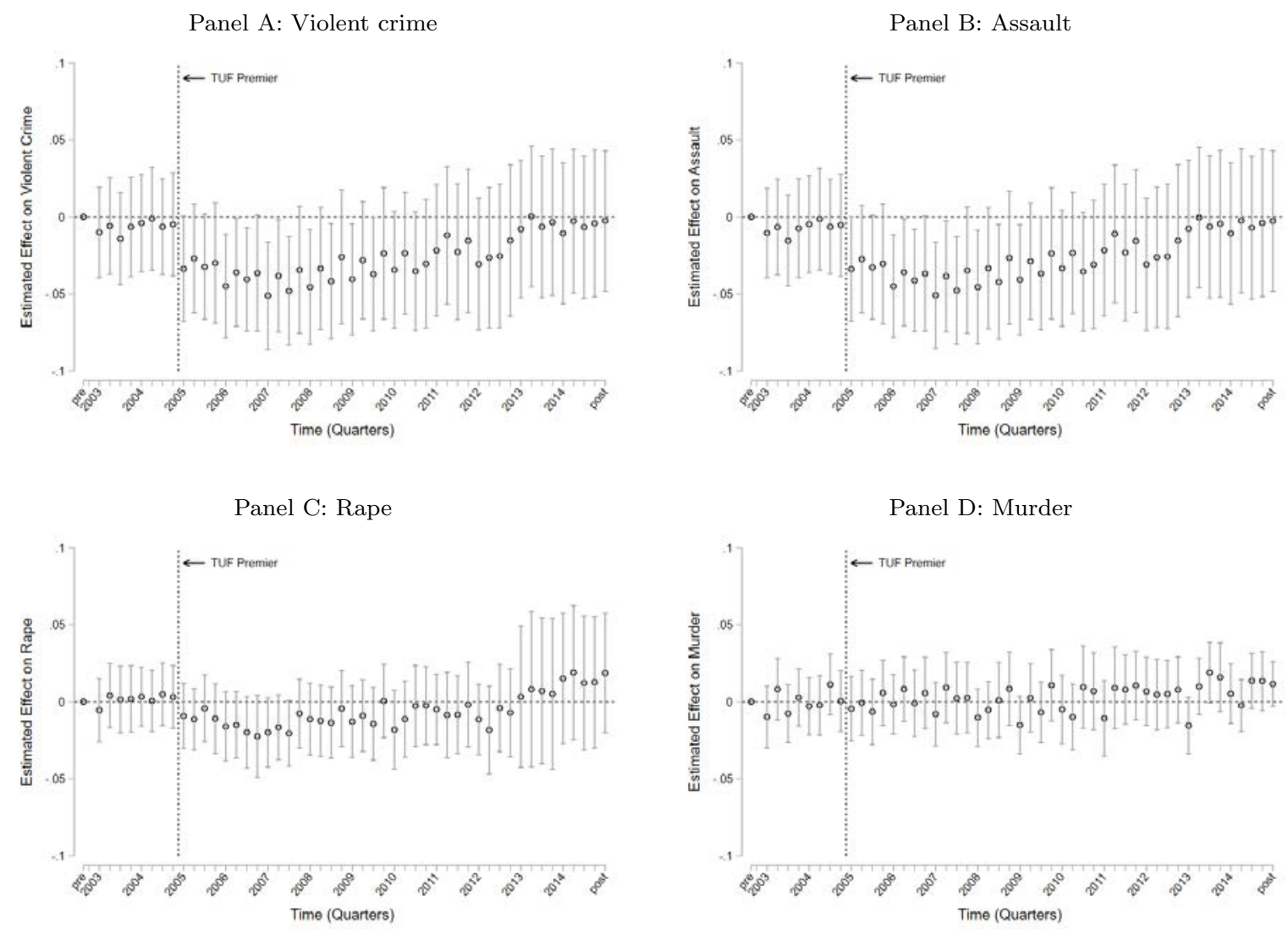

Notes: This figure shows the reduced-form estimates corresponding to the two-stage-least-squares estimates shown in Figure 5. 


\section{Figure A8}

Reduced-form estimates of the effect of 2004 viewership ratings on property crimes over time

Panel A: Property crime

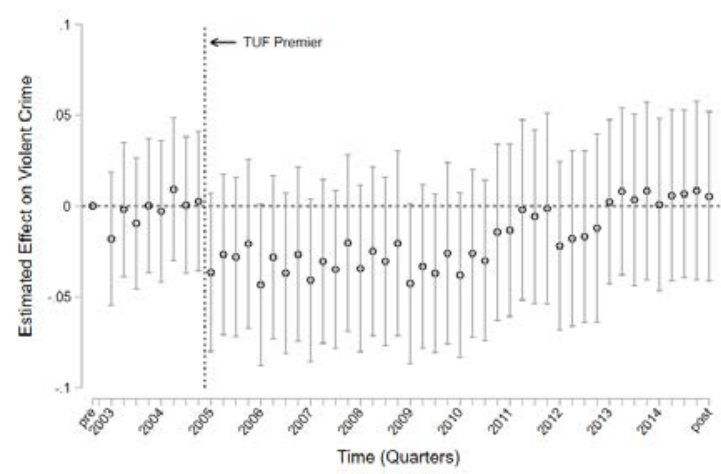

Panel C: Motor-Vehicle Theft

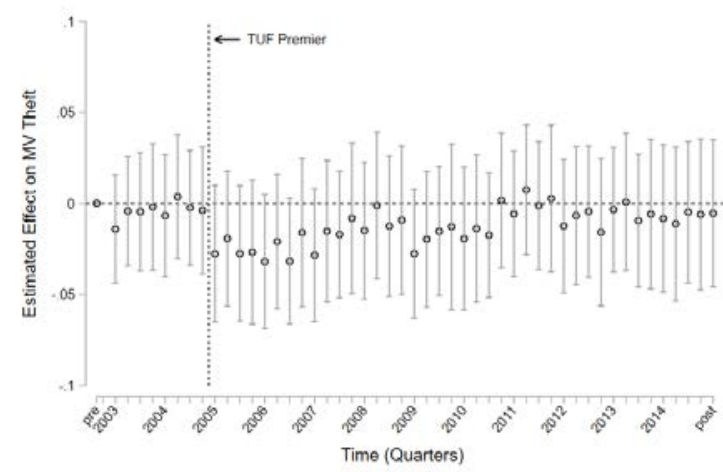

Panel B: Theft

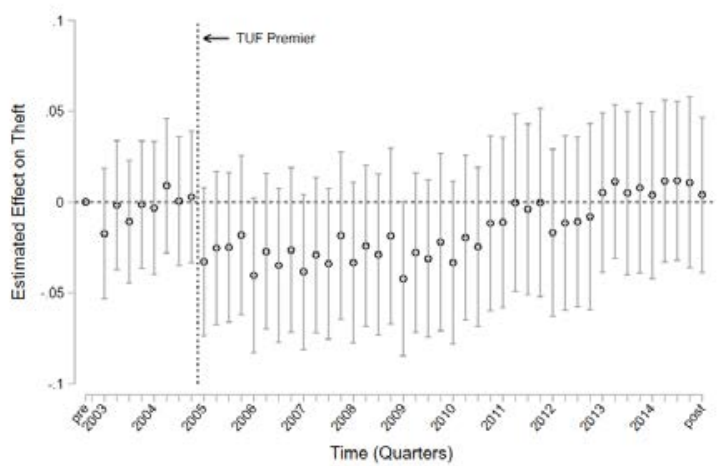

Panel D: Robbery

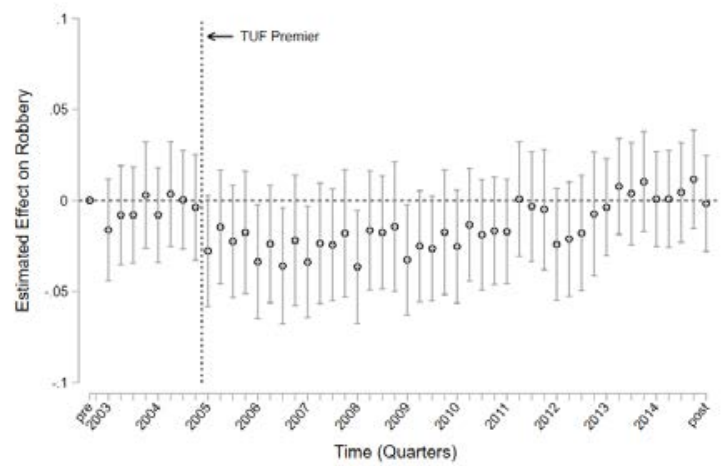

Notes: Notes: This figure shows the reduced-form estimates corresponding to the two-stage-least-squares estimates shown in Figure 6. 
Figure A9

2SLS estimates of the effect of Season 1 TUF viewership on violent crime with separate estimates for each month during the quarter before and after its premier

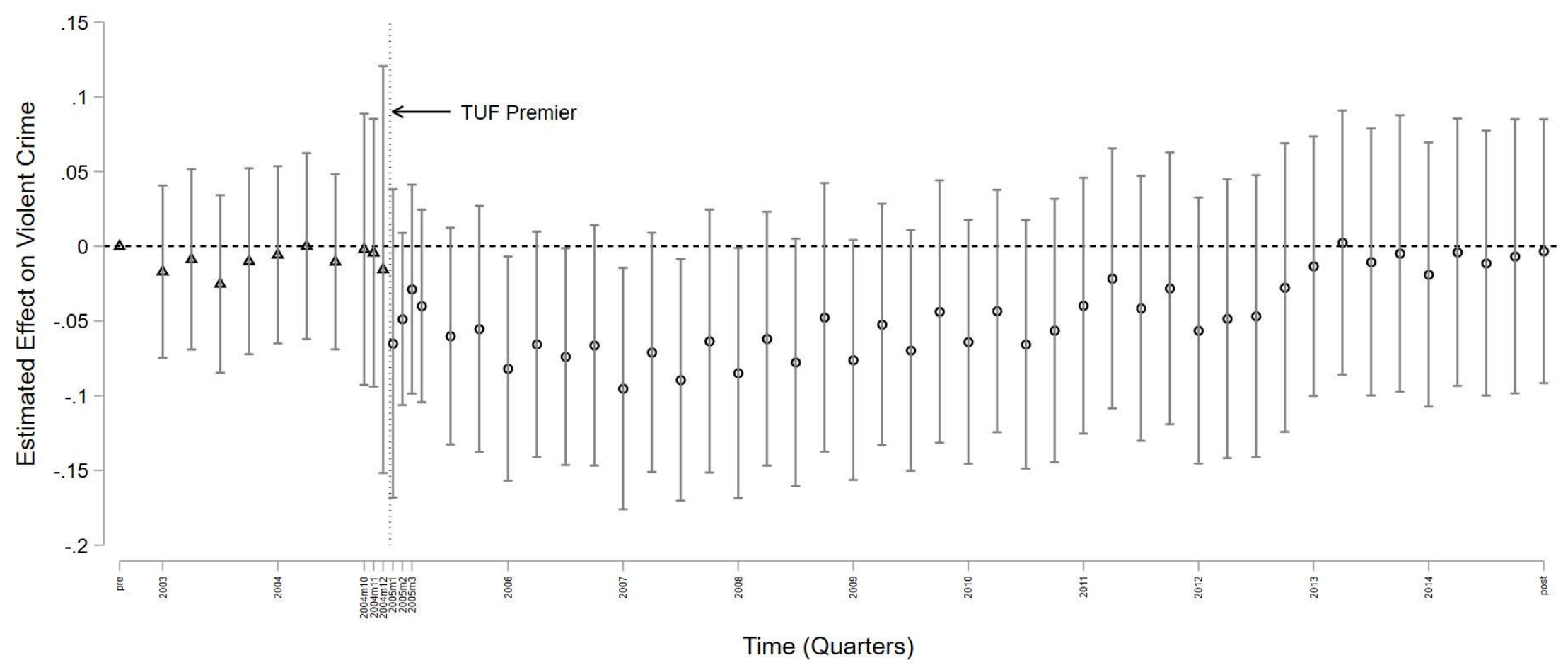

Notes: This figure is the same as the graphic for violent crime in Figure 5, except here we present separate estimates for each month in the quarter before and the quarter after TUF began airing. For visual clarity, we depict the estimated effects prior to TUF as triangles and the estimated effects after TUF began airing as circles. 